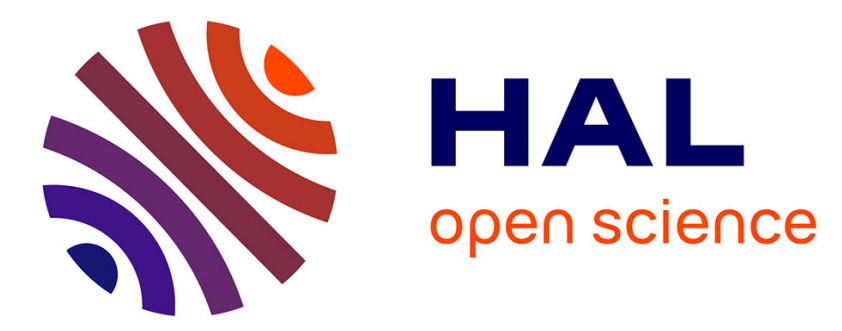

\title{
Microcrystalline Core-Shell Lanthanide-Based Coordination Polymers for Unprecedented Luminescent Properties
}

\author{
Ahmad Abdallah, Carole Daiguebonne, Yan Suffren, Amandine Rojo, Valérie \\ Demange, Kevin Bernot, Guillaume Calvez, Olivier Guillou
}

\section{To cite this version:}

Ahmad Abdallah, Carole Daiguebonne, Yan Suffren, Amandine Rojo, Valérie Demange, et al.. Microcrystalline Core-Shell Lanthanide-Based Coordination Polymers for Unprecedented Luminescent Properties. Inorganic Chemistry, 2019, 58 (2), pp.1317-1329. 10.1021/acs.inorgchem.8b02815 . hal01989013

\section{HAL Id: hal-01989013 https://hal.science/hal-01989013}

Submitted on 13 May 2019

HAL is a multi-disciplinary open access archive for the deposit and dissemination of scientific research documents, whether they are published or not. The documents may come from teaching and research institutions in France or abroad, or from public or private research centers.
L'archive ouverte pluridisciplinaire HAL, est destinée au dépôt et à la diffusion de documents scientifiques de niveau recherche, publiés ou non, émanant des établissements d'enseignement et de recherche français ou étrangers, des laboratoires publics ou privés. 


\section{Microcrystalline core-shell lanthanide-based coordination polymers for unprecedented}

\section{luminescent properties.}

Ahmad Abdallah, Carole Daiguebonne*, Yan Suffren, Amandine Rojo, Valérie Demange, Kevin Bernot, Guillaume Calvez and Olivier Guillou*

Univ Rennes, INSA Rennes, CNRS UMR 6226 "Institut des Sciences Chimiques de Rennes", F-35000 Rennes.

* To whom correspondence should be addressed. 
ABSTRACT.

Microcrystalline core-shell powders of lanthanide-based coordination polymers with general chemical formula $\left([\mathrm{Ln}(\mathrm{cpbOH})]_{\infty}\right)_{1-\mathrm{x}} @\left(\left[\mathrm{Ln}^{\prime}(\mathrm{cpbOH})\right]_{\infty}\right)_{\mathrm{x}}$ with $\mathrm{Hcpb}=$ 1,4-carboxyphenylboronic acid, have been synthesized and structurally characterized. Their luminescent properties have been studied. They are drastically different from those of hetero-lanthanide coordination polymers, also called "molecular alloys", that present same crystal structure and chemical composition. Study of the photo-physical properties of core-shell lanthanide-based coordination polymers reveals that it is possible to control efficiently the inter-metallic energy transfers between lanthanide ions. Furthermore, multi-emissive compounds, under unique irradiation, in both visible and infra-red regions are easily feasible. Core-shell micro-structured lanthanide-based coordination polymers have also been prepared with terephthalic $\left(\mathrm{H}_{2} \mathrm{bdc}\right)$ and trimesic $\left(\mathrm{H}_{3} \mathrm{tma}\right)$ acids as ligands for evidencing that lanthanide ions-based coordination compounds are excellent candidates for 3D molecular epitaxial growth. 


\section{INTRODUCTION}

For about a decade, lanthanide-based coordination polymers arouse a growing interest because of their potential applications in various fields such as lighting and display, ${ }^{1-5}$ chemical sensing, ${ }^{6-8}$ molecular thermometric probes $^{9-11}$ or taggants usable in fight against counterfeiting ${ }^{12-16}$ for examples. Because of their similar chemical properties, ${ }^{17-18}$ lanthanide ions most often lead to series of isostructural coordination polymers when associated with a given ligand. The first example of hetero-lanthanide coordination polymer has been reported by Zhou et al. ${ }^{19}$ at the end of the twentieth century. In these compounds, it has been shown that lanthanide ions are randomly distributed over the metallic sites of the crystal structures. ${ }^{20-}$ ${ }^{22}$ For this reason they have been named molecular alloys ${ }^{23}$ (Scheme 1).

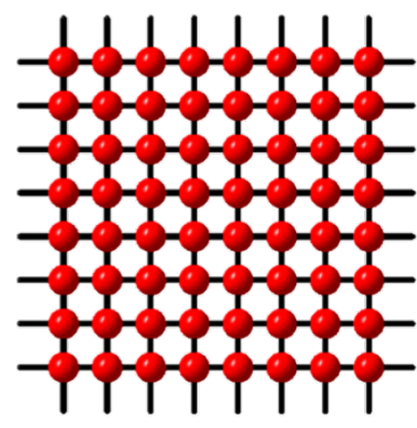

homo-lanthanide
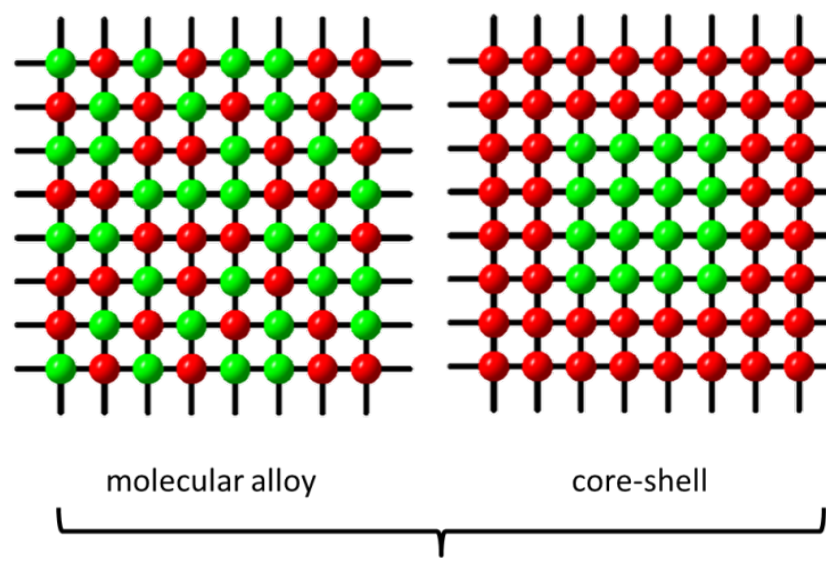

hetero-lanthanide

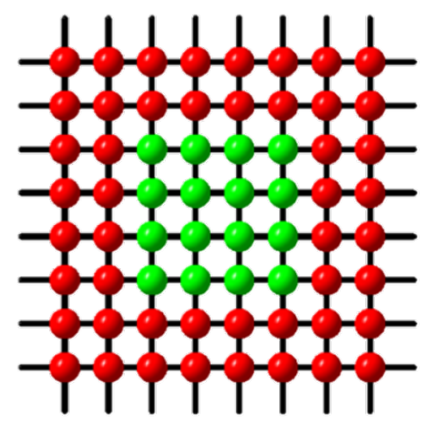

core-shell

Scheme 1. 2D schematic representations of the different type of compounds referenced hereafter. Different ball colors symbolize different lanthanide ions and black rods represent ligands

Therefore it is possible to construct extended families of iso-structural hetero-lanthanide-based coordination polymers in which intensity and color of the emission can be both controlled by a judicious choice of the different lanthanide ions contents. ${ }^{24-33}$ These compounds have already proved their efficiency as far as luminescent taggants of guest materials are targeted. ${ }^{34-35}$ However, in these systems inter-metallic energy transfer can sometimes constitute a drawback for the design of efficient multi-emissive materials. Actually 
examples of coordination polymers that exhibit luminescence under a unique irradiation in both the IR and the visible regions are quite scarce. ${ }^{24}$

Because of their chemical similarity, lanthanide ions are ideal metal ions for 3D molecular epitaxial growth. Indeed their similar chemical behavior, that most often induces series of iso-structural coordination compounds, constitutes an asset for achieving epitaxial growth. Examples of 3D molecular epitaxial growth of complexes ${ }^{36-37}$ or coordination polymers $^{38-50}$ already exist in the literature but, surprisingly, there are very few examples that involve lanthanide ions. ${ }^{37,}{ }^{49-50}$ Moreover, all publications devoted to lanthanide-based coordination compounds describe multi-pot syntheses in which crystals that constitute the cores are first isolated from their mother solution and then immerged in another solution for constructing the shells. As a consequence these synthetic methods can only lead to single or bulk crystals.

In this paper we would like to describe the first example of microcrystalline powders of core-shell lanthanide coordination polymers. Their one-pot synthesis allows the preparation of great amounts of microcrystalline powder with homogenous composition. Their luminescent properties are described and compared with those of the corresponding molecular alloys that present same crystal structures and chemical compositions. Because of the absence of inter-metallic energy transfer between metal ions that belong to the core and metal ions that constitute the shell, these core-shell compounds exhibit different and brighter luminescence. At last, it is possible to use this one-pot synthesis process for designing new compounds that cannot be obtained by traditional synthesis methods.

\section{EXPERIMENTAL SECTION.}

1,4-carboxyphenylboronic acid (Hcpb) was purchased from TCI (>90\%) and used without further purification. Its sodium salt $\left(\mathrm{Nacpb} \cdot 1.5 \mathrm{H}_{2} \mathrm{O}\right)$ was prepared according to 
previously reported procedure. ${ }^{51}$ Lanthanide oxides (4N) were purchased from AMPERE and used without further purification. Lanthanide chlorides were prepared according to literature. ${ }^{18}$ Trimesic acid ( $\left.\mathrm{H}_{3} \mathrm{tma}\right)$ (98\%) and terephthalic acid $\left(\mathrm{H}_{2}\right.$ bdc) $(>99 \%)$ were purchased from Alfa Aesar and TCI respectively and used without further purification. Their sodium salts were prepared as previously described. ${ }^{52,53}$

Synthesis of the micro-crystalline powders of homo-lanthanide coordination polymers: $[\operatorname{Ln}(\mathbf{c p b O H})]_{\infty}$ with Ln = Pr-Lu.

Stoichiometric amounts of a lanthanide chloride $(0.5 \mathrm{mmol}$ in $10 \mathrm{~mL})$ and of Nacpb $1.5 \mathrm{H}_{2} \mathrm{O}(1 \mathrm{mmol}$ in $10 \mathrm{~mL})$ were dissolved separately in deionized water. The two solutions were mixed and stirred for 40 minutes at room temperature. Precipitation occurs. Precipitate was filtered rinsed with water and dried at ambient pressure and room-temperature. The yields were about $90 \%$ whatever the involved lanthanide ion was. ${ }^{54}$ Compounds that constitute this series have been assumed to be isostructural to $\left[\mathrm{Tb}(\mathrm{cpbOH})\left(\mathrm{H}_{2} \mathrm{O}\right)_{2} \cdot(\mathrm{cpb})\right]_{\infty}$ on the basis of their powder diffraction diagrams. ${ }^{54}$ They are hereafter abbreviated as $[\mathrm{Ln}(\mathrm{cpbOH})]_{\infty}$. Positions of the diffraction peaks of these powder diffraction patterns were extracted, indexed and refined. Refined cell parameters present almost no variation from Pr- to Lu-based homo-lanthanide compounds (see Table S1) which is mandatory for 3D molecular epitaxial growth.

Synthesis of the micro-crystalline powders of hetero-lanthanide molecular alloys coordination polymers: $\left[\operatorname{Ln}_{1-x} L_{n}^{\prime}(c p b O H)\right]_{\infty}$ with $\operatorname{Ln}$ or $L^{\prime} n^{\prime}=$ Pr-Lu except Pm plus Y and $0 \leq x \leq 1$.

Synthesis of the molecular alloys is similar to that of the homo-lanthanide coordination polymers described above. The only difference is that the solution of lanthanide 
chloride is replaced by a solution of the appropriate mixture of lanthanide chlorides. Relative contents of the different lanthanides in the coordination polymers have been estimated by EDS (Table S2). On the basis of their powder diffraction diagram, these molecular alloys have all been assumed to be isostructural to $[\mathrm{Tb}(\mathrm{cpbOH})]_{\infty}{ }^{51}$

Synthesis of the micro-crystalline powders of hetero-lanthanide core-shell coordination polymers: $\left([\operatorname{Ln}(\mathrm{cpbOH})]_{\infty}\right)_{1-\mathrm{x}} @\left(\left[\operatorname{Ln}^{\prime}(\mathrm{cpbOH})\right]_{\infty}\right)_{\mathrm{x}}$ with Ln or Ln' = Pr-Lu except Pm plus $Y$ and $0 \leq x \leq 1 .^{[55]}$

An aqueous solution of a lanthanide chloride $(0.5-\mathrm{x} \mathrm{mmol}$ in $5 \mathrm{~mL})$ and an aqueous solution of Nacpb $1.5 \mathrm{H}_{2} \mathrm{O}(1 \mathrm{mmol}$ in $10 \mathrm{~mL})$ were mixed and stirred at room temperature for 1 hour for insuring complete precipitation. The obtained suspension is made of microcrystals that will constitute the cores of the final core-shell microcrystalline powder. To this suspension, vigorously stirred, a second diluted solution of the other lanthanide chloride (x mmol in $10 \mathrm{~mL}$ ) is added dropwise in order to avoid local over-concentration. During addition, concentration of the second lanthanide chloride rises and reaches solubility product of the second coordination polymer. Microcrystals of the first coordination polymer act as nucleation cores and the second coordination polymer grows around them, forming shells (Scheme 2).

Relative contents of the different lanthanides in the coordination polymers have been estimated by Energy Dispersive Spectroscopy (Table S2). On the basis of their powder diffraction diagrams, these core-shell compounds have all been assumed to be isostructural to $[\mathrm{Tb}(\mathrm{cpbOH})]_{\infty}$. 


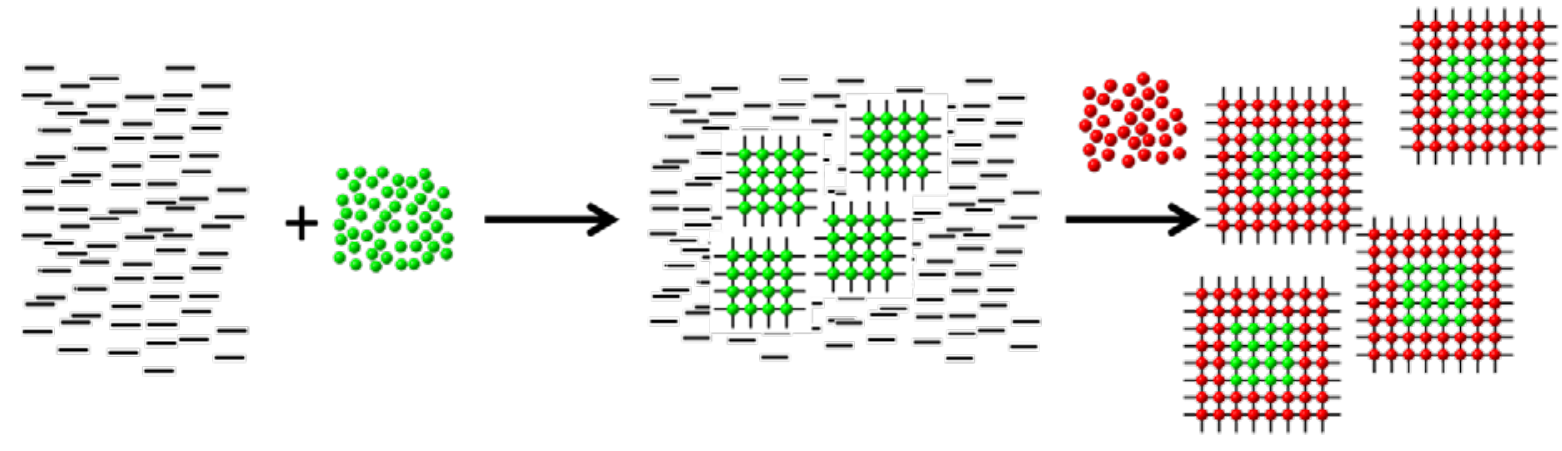

Scheme 2. Schematic representation of the core-shell particles preparation

This method is general for lanthanide coordination compounds and, for the other coordination polymers, based on terephthalic or trimesic acids, procedures are similar to those described above.

\section{Powder X-ray diffraction.}

Experimental powder diffraction diagrams have been collected with a Panalytical X'pert Pro diffractometer equipped with a X'Celerator detector. Typical recording conditions were $45 \mathrm{kV}, 40 \mathrm{~mA}$ for $\mathrm{CuK}_{\alpha}(\lambda=1.542 \AA)$ in $\theta / \theta$ mode. Calculated patterns were produced using the Powdercell and WinPLOTR software packages. ${ }^{56-58}$ For pattern indexing, extraction of the positions of the peaks were done using the WinPLOTR program. Pattern indexing was performed using McMaille software ${ }^{59}$ and refinement of the cell parameters by the Chekcell program. $^{60}$

\section{Electron microscopies and Energy Dispersive Spectroscopy.}

Scanning electron microscopy (SEM) observations have been performed with a Hitachi TM-1000, Tabletop Microscope version 02.11 (Hitachi High-Technologies, Corporation Tokyo Japan) with Energy Dispersive Spectroscopy (EDS) analysis system (SwiftED-TM, Oxford Instruments Link INCA). Samples were assembled on carbon discs, 
stuck on an aluminium stub fixed at $7 \mathrm{~mm}$ from EDS beam, with an angle of measurement of $22^{\circ}$. Reproducibility of the elemental analyses has been checked by repeating the measurements several times. These experiments support the homogeneity of the samples.

Elemental mappings were obtained by scanning transmission electron microscopy in high angle annular darkfield mode (HAADF-STEM) performed at $80 \mathrm{kV}$ with a Jeol 2100 instrument equipped with an EDS Oxford Aztec system.

\section{Optical and colorimetric measurements.}

Solid state emission and excitation spectra have been measured on a Horiba Jobin-Yvon Fluorolog III fluorescence spectrometer equipped with a Xe lamp 450 W, a UV-Vis photomultiplier (Hamamatsu R928, sensitivity 190-860 nm). Most of the luminescence spectra were recorded at room temperature. The emission/excitation spectra recordings were realized on powder samples introduced in cylindrical quartz cells of $0.7 \mathrm{~cm}$ diameter and $2.4 \mathrm{~cm}$ height, which were placed directly inside the integrating sphere, or on powder samples introduced in quartz capillary tubes or on powder samples pasted on copper plates with a silver lacquer. Emissions at variable temperature were performed with an optical cryostat coupled with an external liquid nitrogen bath, able to reach temperature of $77 \mathrm{~K}$ under nitrogen gas atmosphere. Luminescence decays have also been measured at room temperature using this apparatus with a Xenon flash lamp (phosphorescence mode). Lifetimes are averages of two or three independent determinations. Appropriate filters were used to remove the residual excitation laser light, the Rayleigh scattered light and associated harmonics from spectra. All spectra were corrected for the instrumental response function.

Luminescence intensities of the samples expressed in Cd.m ${ }^{-2}$ have been measured with a Gigahertz-Optik X1-1 optometer with an integration time of $200 \mathrm{~ms}$ on $1.5 \mathrm{~cm}^{2}$ pellets under UV irradiation ( $\lambda_{\mathrm{exc}}=312 \mathrm{~nm}$ ). The intensity of the UV flux at sample location, 
0.68(1) $\mathrm{mW} . \mathrm{cm}^{-2}$, has been measured with a VilberLourmat VLX-3W radiometer. $\left[\mathrm{Tb}_{2}(\mathrm{bdc})_{3} \cdot 4 \mathrm{H}_{2} \mathrm{O}\right]_{\infty}$ where bdc $^{2-}$ stands for terephthalate was used as a standard. Its luminance is $99(1)$ Cd.m $\mathrm{m}^{-2}$ under these operating conditions $\left(\lambda_{\text {exc }}=312 \mathrm{~nm}\right.$; flux $\left.=0.68(1) \mathrm{mW} \cdot \mathrm{cm}^{-2}\right) .^{21}$

The CIE (Commission Internationale de l'Eclairage) (x, y) emission color coordinates $^{61-62}$ were obtained using a MSU-003 colorimeter (Majantys) with the PhotonProbe 1.6.0 Software (Majantys). Color measurements: $2^{\circ}$, CIE 1931, step 5 nm, under $312 \mathrm{~nm} \quad \mathrm{UV}$ light. $\mathrm{X}=k \times \int_{380 \mathrm{~nm}}^{780 \mathrm{~mm}} I_{\lambda} \times x_{\lambda}, \quad \mathrm{Y}=k \times \int_{380 \mathrm{~nm}}^{780 \mathrm{~mm}} I_{\lambda} \times y_{\lambda} \quad$ and $\quad \mathrm{Z}=k \times$ $\int_{380 \mathrm{~nm}}^{780 \mathrm{~nm}} I_{\lambda} \times z_{\lambda}$ with $\mathrm{k}$ constant for the measurement system $\mathrm{I}_{\lambda}$ sample spectrum intensity, wavelength depending, $\mathrm{x}_{\lambda}, \mathrm{y}_{\lambda}, \mathrm{z}_{\lambda}$ trichromatic values $\mathrm{x}=\mathrm{X} /(\mathrm{X}+\mathrm{Y}+\mathrm{Z}), \mathrm{y}=\mathrm{Y} /(\mathrm{X}+\mathrm{Y}+\mathrm{Z})$ and $\mathrm{z}=\mathrm{Z} /(\mathrm{X}+\mathrm{Y}+\mathrm{Z})$. Mean $\mathrm{xyz}$ values are given for each sample, which act as light sources (luminescent samples). Standards from Phosphor Technology used, calibrated at $312 \mathrm{~nm}$ : red phosphor $\mathrm{Gd}_{2} \mathrm{O}_{2} \mathrm{~S}$ :Eu $(\mathrm{x}=0.667, \mathrm{y}=0.330)$ and green phosphor $\mathrm{Gd}_{2} \mathrm{O}_{2} \mathrm{~S}: \mathrm{Tb}(\mathrm{x}=0.328$, $\mathrm{y}=0.537)$

\section{Optical microscopy.}

Optical microscopy pictures were obtained with an OLYMPUS IX51 inversed optical microscope equipped with a ColorView camera under UV irradiation.

\section{RESULTS AND DISCUSSION.}

\section{a) Core-shell particles vs molecular alloys: $\left([\operatorname{Ln}(\mathbf{c p b O H})]_{\infty}\right)_{0.5} @\left(\left[\operatorname{Ln}^{\prime}(\mathbf{c p b O H})\right]_{\infty}\right)_{0.5}$}

In order to validate our idea, we have first worked with lanthanide coordination polymers based on 1,4-carboxyphenylboronic (Hcpb) ligand (Figure 1). This ligand, in association with lanthanide ions, leads to a family of isostructural coordination polymers with general abbreviated chemical formula $[\mathrm{Ln}(\mathrm{cpbOH})]_{\infty}$ with $\mathrm{Ln}=$ Pr-Lu except Pm plus $\mathrm{Y}^{54}$ in which inter-metallic energy transfers have been proved to be particularly efficient. ${ }^{51}$ 
Additionally, all compounds of these series (homo-lanthanide as well as hetero-lanthanide coordination polymers) can be excited at $303 \mathrm{~nm}^{51}$ thanks to a classical antenna effect. ${ }^{63}$
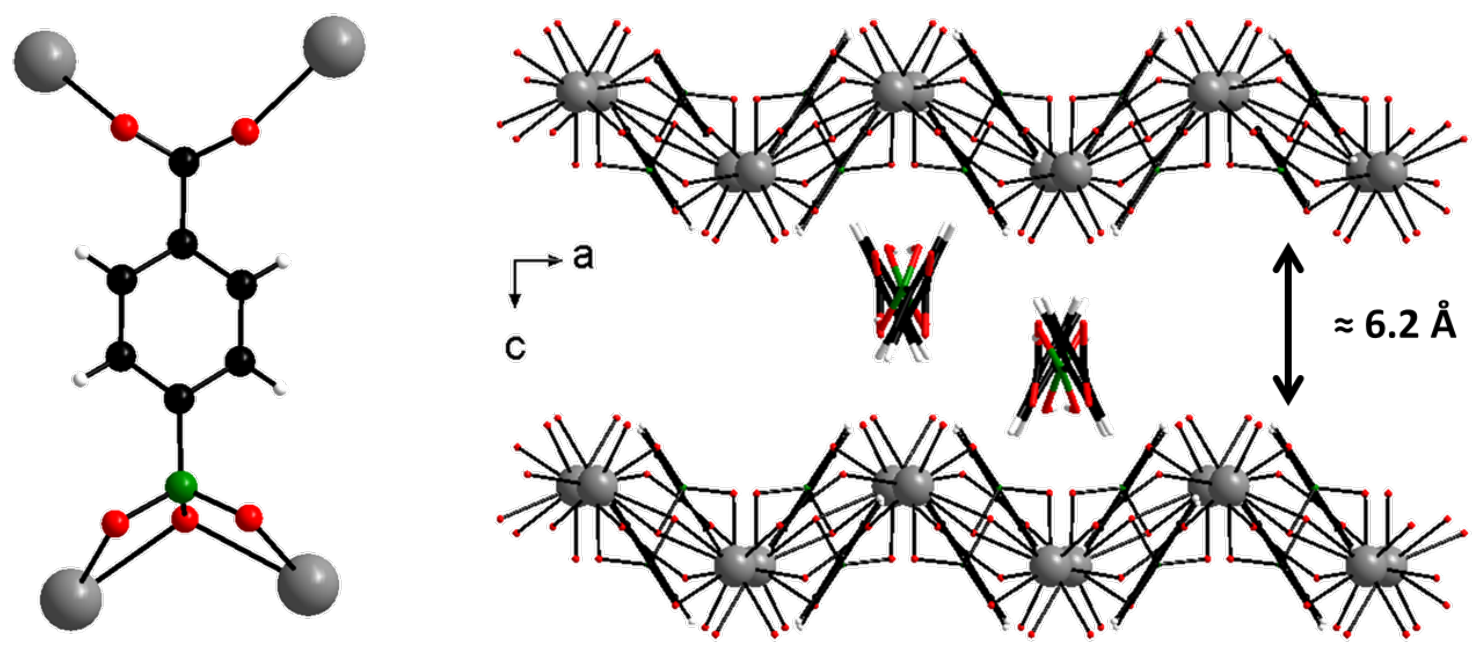

Figure 1. Left: Projection view of 1,4-carboxyphenylboronate ligand ( $\left.\mathrm{cpbOH}^{2-}\right)$. Right: Projection view along the $b$ axis of $[\mathrm{Tb}(\mathrm{cpbOH})]_{\infty}$. Molecules drawn in "wires or sticks" model are the free $\mathrm{cpb}^{-}$ligands that are located between the wavy molecular planes. $[\mathrm{Tb}(\mathrm{cpbOH})]_{\infty}$ crystallizes in the orthorhombic system, space group Pbca ( ${ }^{\circ}$ 61) with the following cell parameters: $a=8.5704(1) \AA, \quad b=19.5441(1) \AA, \quad c=21.4191(3) \AA$, $V=3587.71(7) \AA^{3}$ and $Z=8$. (CCDC-962513). Redrawn from reference 54.

This crystal structure is $2 \mathrm{D}$ and can be described as the superimposition of wavy planes that spread parallel to the $a b$ plane. These molecular planes are quite far from each other $\left(\approx 6 \AA\right.$ ) and isolated $\mathrm{cpb}^{-}$ligands that insure the electro-neutrality of the crystal packing are located in the inter-plane space.

Three samples with similar chemical compositions have been prepared and compared (Figure 2): (i) the molecular alloy with chemical formula $\left[\mathrm{Tb}_{0.5} \mathrm{Eu}_{0.5}(\mathrm{cpbOH})\right]_{\infty}$; (ii) the core-shell with chemical formula $\left([\mathrm{Tb}(\mathrm{cpbOH})]_{\infty}\right)_{0.5} @\left([\mathrm{Eu}(\mathrm{cpbOH})]_{\infty}\right)_{0.5}$; (iii) the equimolar mixture of microcrystalline powders of $[\mathrm{Tb}(\mathrm{cpbOH})]_{\infty}$ and $[\mathrm{Eu}(\mathrm{cpbOH})]_{\infty}$ (physical mixture). All these microcrystalline powders present similar chemical composition, X-ray powder diffraction patterns and particles morphologies (Figure 2).

SEM pictures of Figure 2 show that core-shell particles are a bit bigger than molecular alloy ones. This can be related to the fact that crystallization nuclei are less numerous in the 
chemical process that leads to core-shell particles than in the one that leads to molecular alloy particles.
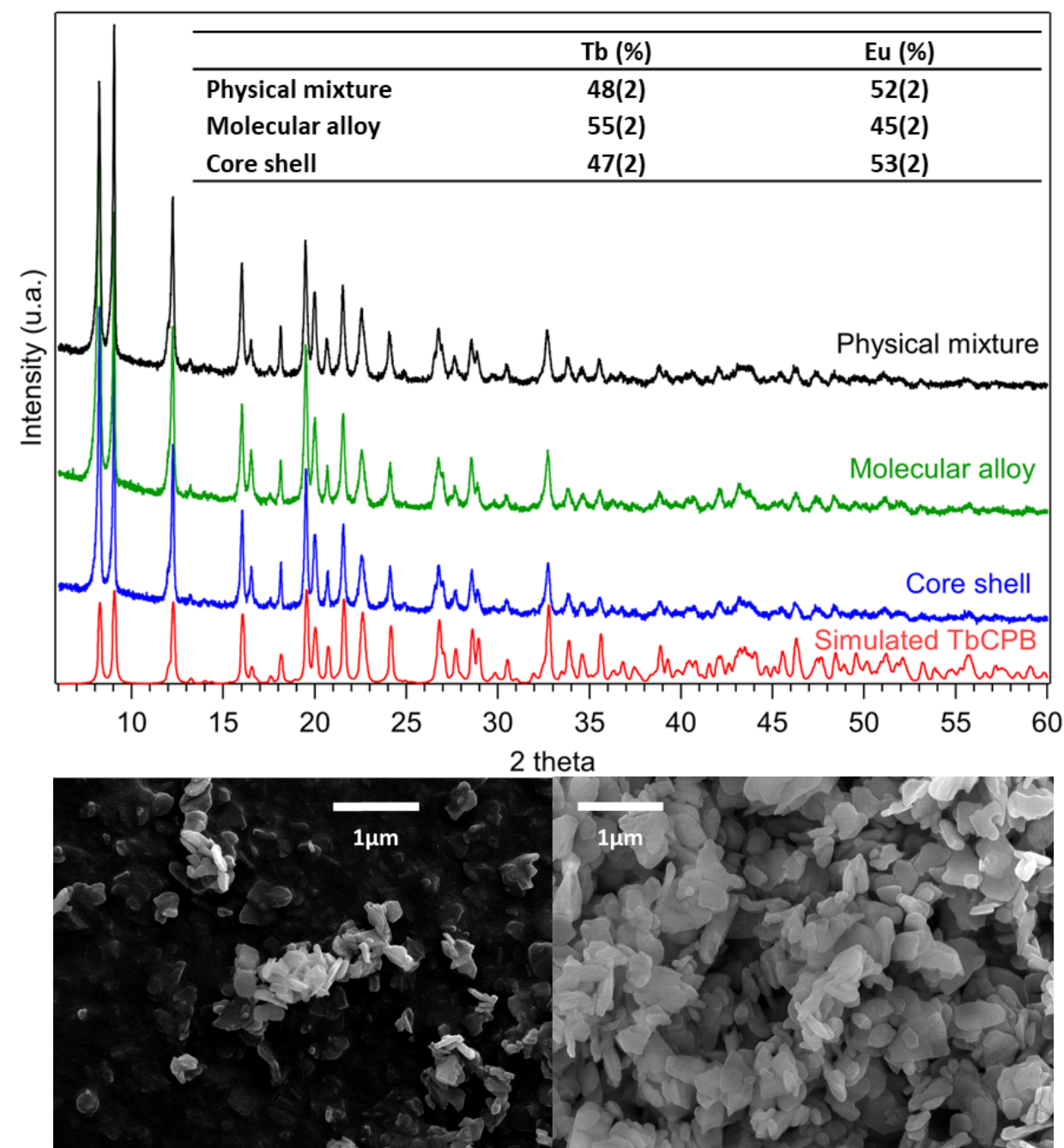

Figure 2. Top: Experimental powder diffraction diagrams of the three samples (physical mixture, molecular alloy and core-shell) measured at $300 \mathrm{~K}$ and simulated X-ray diffraction diagram of $[\mathrm{Tb}(\mathrm{cpbOH})]_{\infty}$ on the basis of its crystal structure $(150 \mathrm{~K})$. In inset, $\mathrm{Eu}^{3+}$ and $\mathrm{Tb}^{3+}$ contents measured by EDS. Bottom: SEM pictures of the molecular alloy (left) and the core-shell (right).

Despite their chemical and structural similarities, these three microcrystalline powders present drastically different luminescence properties (Figure 3).

Indeed, in molecular alloy, $\mathrm{Eu}^{3+}$ and $\mathrm{Tb}^{3+}$ are quite close from each other and there are about four $\mathrm{Eu}^{3+}$ in the vicinity of a given $\mathrm{Tb}^{3+}$ ions ${ }^{51}$ (closer than $10 \AA$, the distance above which intermetallic energy transfers become less efficient). ${ }^{64-65}$ Therefore, as expected, an efficient Tb-to-Eu intermetallic energy transfer occurs that leads to an enhancement of the red 
luminescence of $\mathrm{Eu}^{3+}$ ions accompanied by a drastic diminution of the green luminescence of $\mathrm{Tb}^{3+}$ ions. As a consequence, a red luminescence is observed (See Figure 3). Colorimetric coordinates are: $x=0.60(1)$ and $y=0.33(1)$.

On the opposite, for the physical mixture of homo-lanthanide coordination polymers, distances between adjacent crystallites are of the order of $10-100 \mathrm{~nm}$ and there is no inter-metallic energy transfer between lanthanide ions that belong to adjacent particles. Therefore, the overall luminescence color of the physical mixture sample is simply the addition of particles that luminesce in the red $\left([\mathrm{Eu}(\mathrm{cpbOH})]_{\infty}\right)$ and of particles that luminesce in the green $\left([\mathrm{Tb}(\mathrm{cpbOH})]_{\infty}\right)$. Because luminance of the Tb-based homo-nuclear compound is greater than the one of the Eu-based homo-nuclear compound, ${ }^{51}$ overall observed luminescence is green (Figure 3). Colorimetric coordinates are: $x=0.41(1)$ and $y=0.51(1)$.

At last, colorimetric coordinates of the core-shell sample $(x=0.47(1)$ and $y=0.48(1))$ show that its luminescence is yellow. This suggests that a very small amount of Tb-to-Eu intermetallic energy-transfer, at the frontier between the core and the shell, is present. On the other hand, Tb-based compound constitute the core of the particles. Evidently, part of the UV irradiation is absorbed or dispersed by the shell which could also explain that red component of the luminescence is greater than the one observed for the physical mixture sample. 

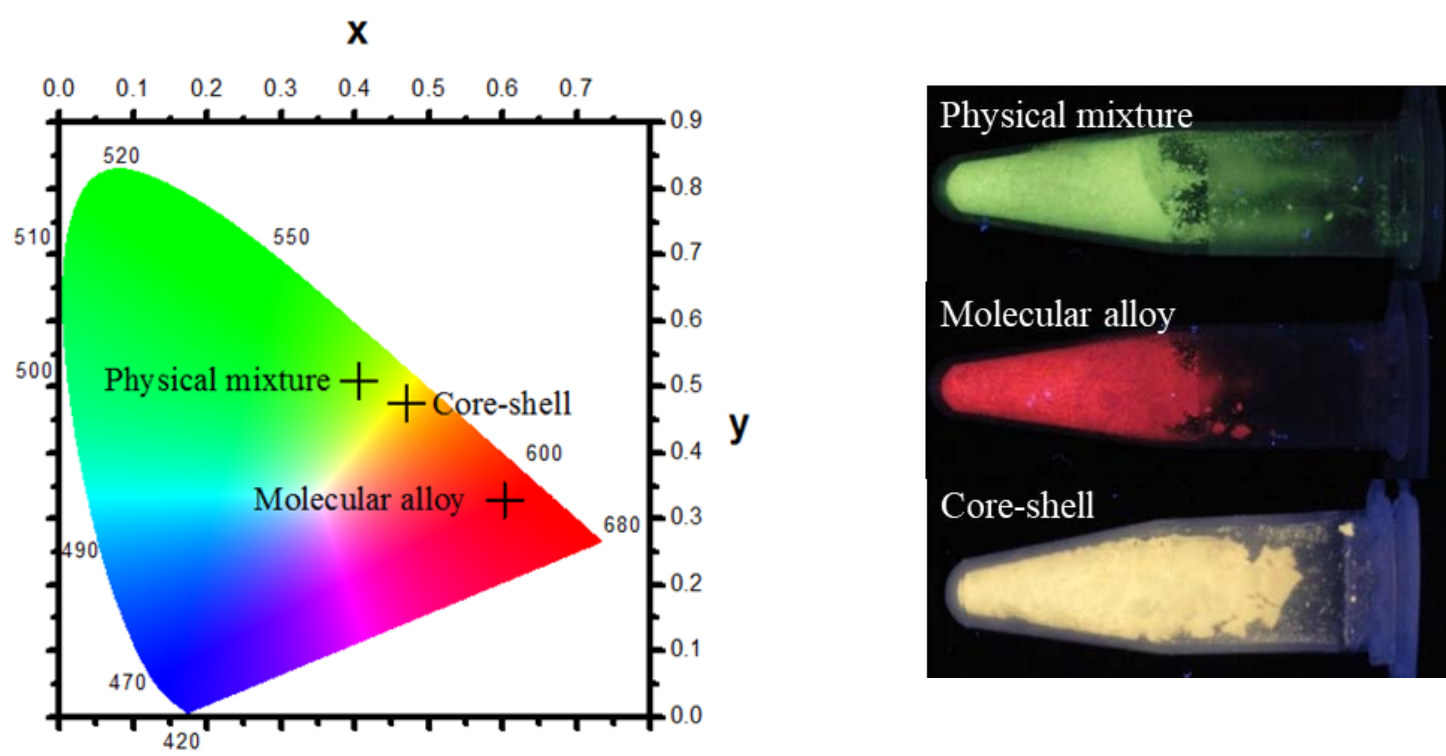

Figure 3. Left: Colorimetric coordinates of the three microcrystalline powders under UV irradiation $\left(\lambda_{\text {exc }}=312 \mathrm{~nm}\right)$. Right: Pictures of the three samples under UV irradiation $\left(\lambda_{\text {exc }}=312 \mathrm{~nm}\right)$.

Pictures under UV irradiation $\left(\lambda_{\text {exc }}=312 \mathrm{~nm}\right)$ of the three microcrystalline samples are reproduced in Figure 4. They evidence that: (i) all particles of the core-shell and of the molecular alloy exhibit homogenous color emission while overall color emission of the physical mixture correspond to the sum of different particles that emit in the red and in the green respectively.

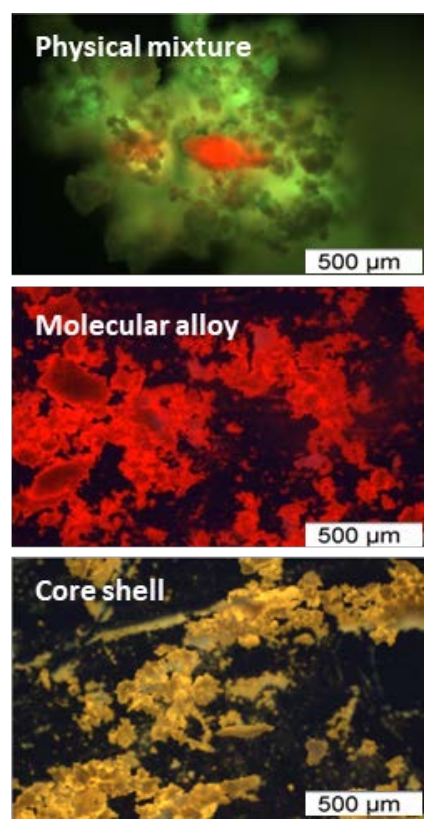

Figure 4. Pictures of the three samples under UV irradiation $\left(\lambda_{\text {exc }}=312 \mathrm{~nm}\right)$ taken with an inversed optical microscope. 
Solid state emission spectra of both the molecular alloy and the core-shell compounds have been recorded (Figure 5) and luminescent lifetimes of $\mathrm{Eu}^{3+}$ and $\mathrm{Tb}^{3+}$ ions have been measured at room-temperature (Table 1 and Figure S1). These measurements confirm that Tb-to-Eu inter-metallic energy transfer is almost absent in the core-shell sample. Indeed, in contrast with what is observed for the molecular alloy sample, luminescent lifetimes of the core-shell sample are almost identical to those measured for the Tb- and Eu-based homo-lanthanide coordination polymers. Moreover, the $\mathrm{Tb}^{3+}$ luminescence is absent in the molecular alloy emission spectrum while it is sizeable in the core-shell one (Figure 5). Energy transfers in both samples are represented in scheme 3.

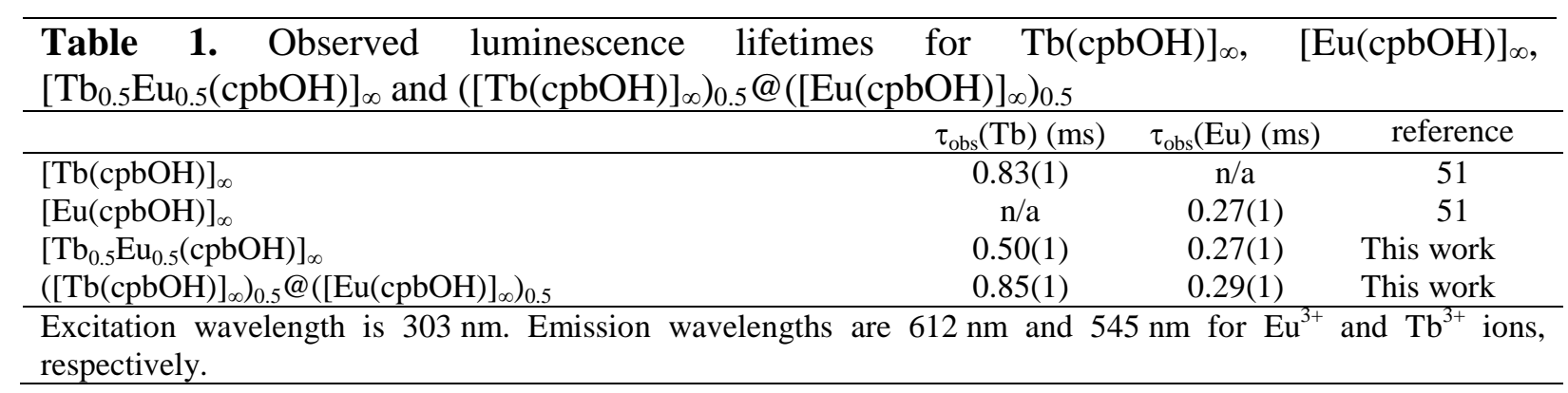



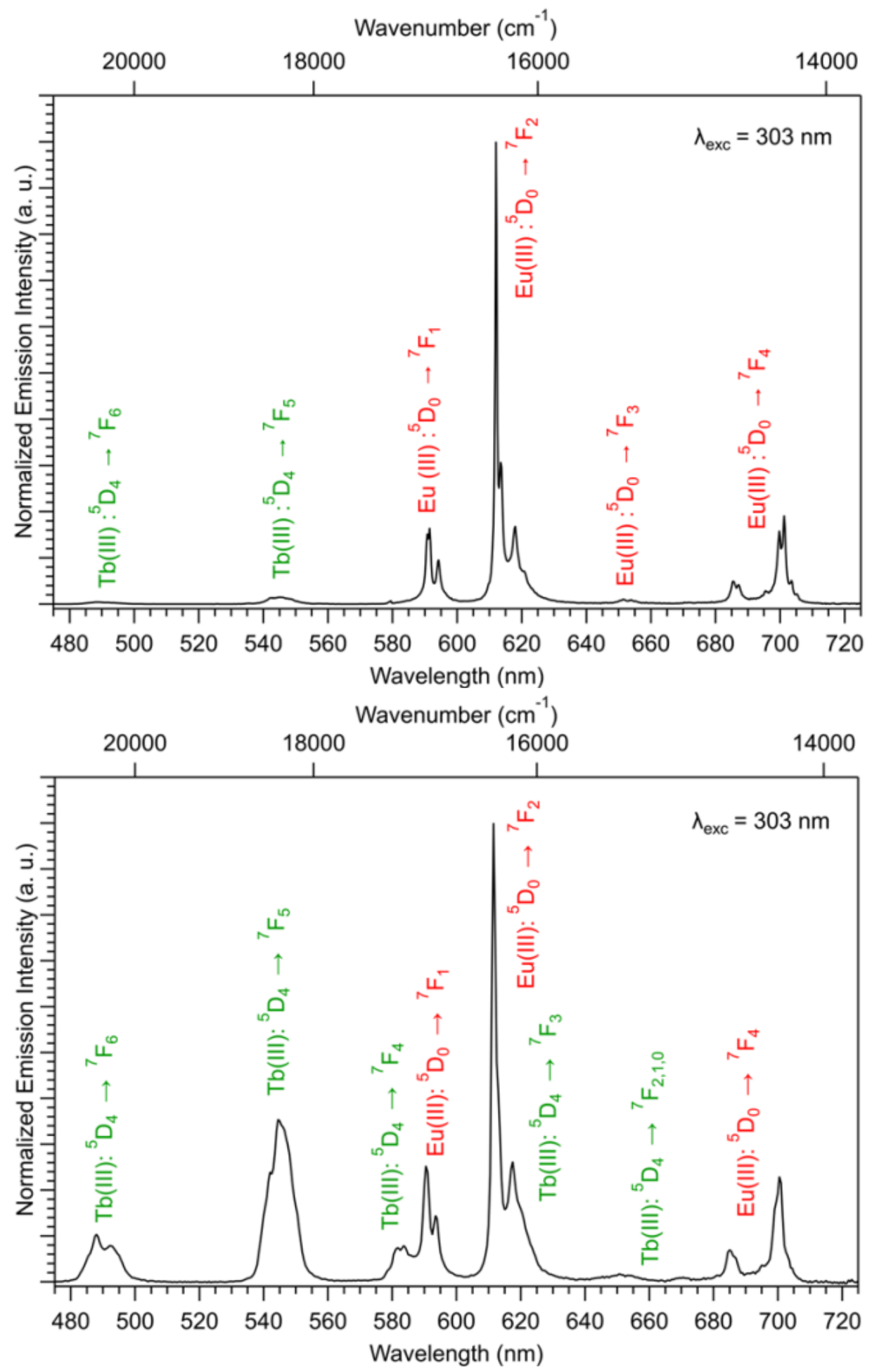

Figure 5. Solid state emission spectra of $\left[\mathrm{Tb}_{0.5} \mathrm{Eu}_{0.5}(\mathrm{cpbOH})\right]_{\infty}$ (top) and $\left([\mathrm{Tb}(\mathrm{cpbOH})]_{\infty}\right)_{0.5} @\left([\mathrm{Eu}(\mathrm{cpbOH})]_{\infty}\right)_{0.5}$ (bottom). 

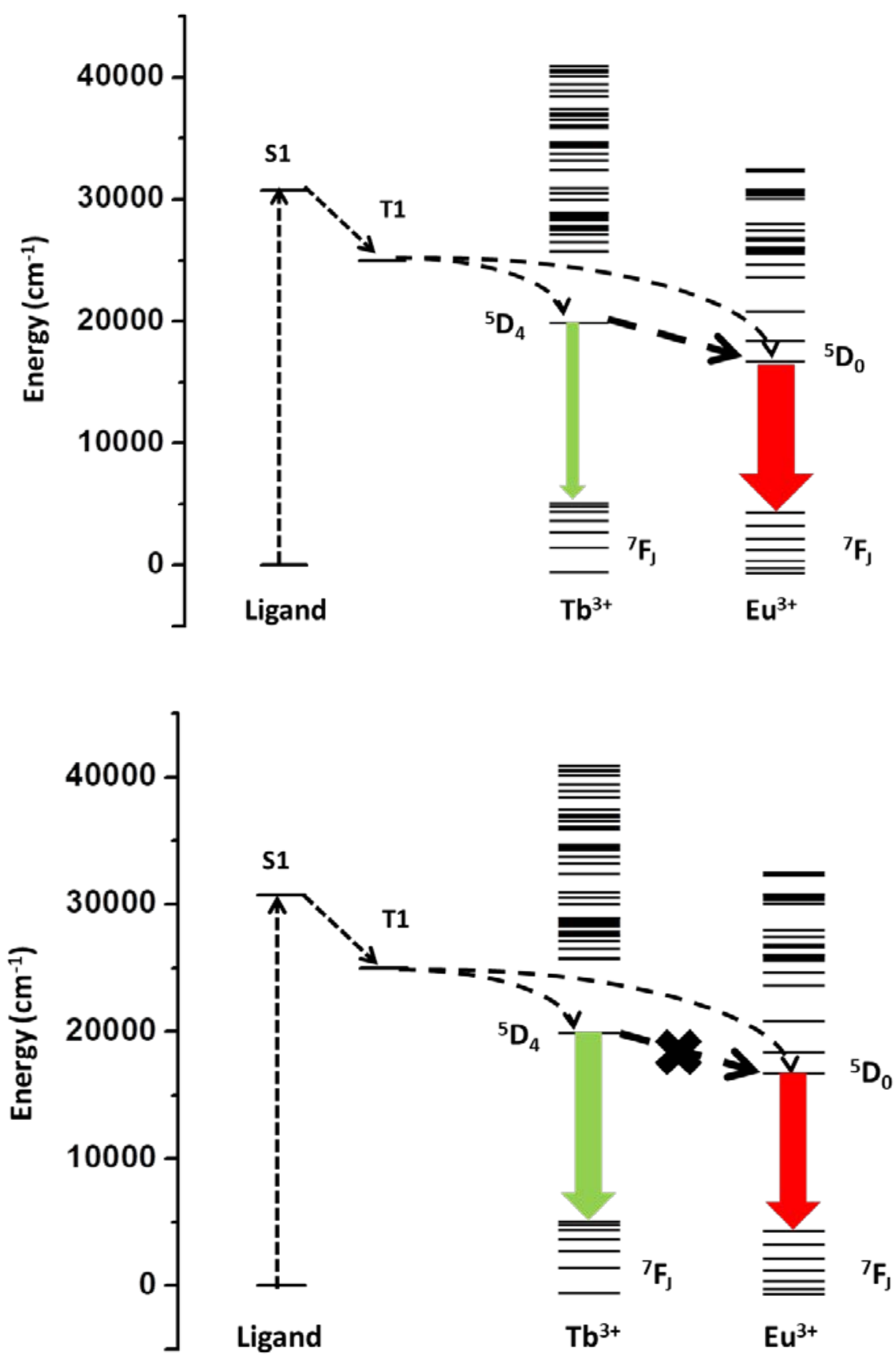

Scheme 3. Simplified Jablonsky's diagrams for $\left[\mathrm{Tb}_{0.5} \mathrm{Eu}_{0.5}(\mathrm{cpbOH})\right]_{\infty}$ (top) and $\left([\mathrm{Tb}(\mathrm{cpbOH})]_{\infty}\right)_{0.5} @\left([\mathrm{Eu}(\mathrm{cpbOH})]_{\infty}\right)_{0.5}$ (bottom)

In order to further demonstrate the core-shell microstructure, we have prepared $\left([\mathrm{Lu}(\mathrm{cpbOH})]_{\infty}\right)_{0.5} @\left([\mathrm{Y}(\mathrm{cpbOH})]_{\infty}\right)_{0.5}$ for recording TEM measurements, because $\mathrm{Lu}^{3+}$ and $\mathrm{Y}^{3+}$ atomic numbers are very different from each other which allows good imaging contrast (Figures 6 and S2). Relative metallic contents have been measured (Table S2) and 
isostructurality of the compound with $[\mathrm{Tb}(\mathrm{cpbOH})]_{\infty}$ has been assumed on the basis of a powder diffraction diagram (Figure S3). EDS maps have been recorded on 3D particles.
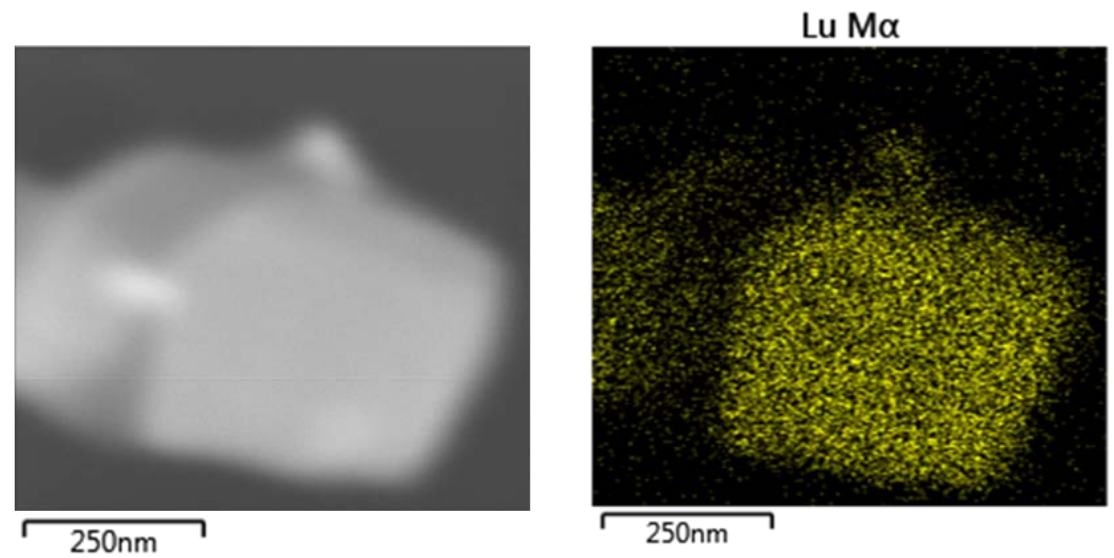

superimposition

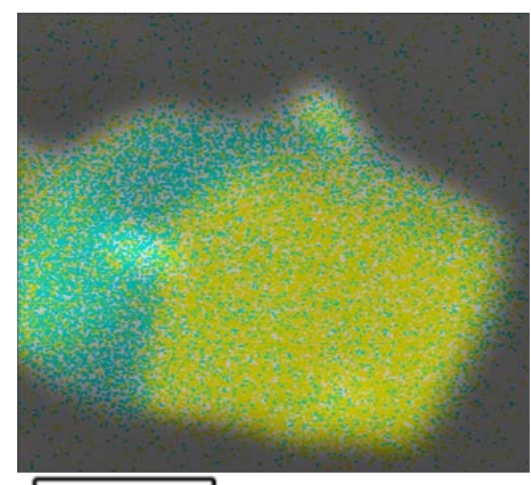

$250 \mathrm{~nm}$

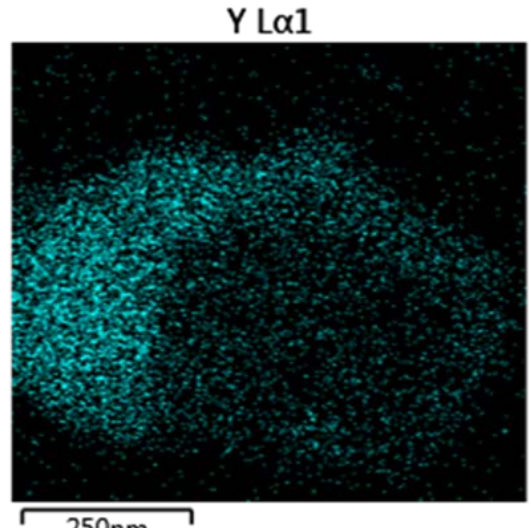

$250 \mathrm{~nm}$

Figure 6. STEM-HAADF micrograph of a core shell particle of $\left([\mathrm{Lu}(\mathrm{cpbOH})]_{\infty}\right)_{0.5} @\left([\mathrm{Y}(\mathrm{cpbOH})]_{\infty}\right)_{0.5}$ (top left). EDS map of the presence of lutetium (top right) and Y (bottom right). Superimposition of the two EDS maps (bottom left).

These measurements clearly indicate that $\mathrm{Y}^{3+}$ ions are concentrated at the periphery of the particle while $\mathrm{Lu}^{3+}$ ions are observed at the center which confirms the core-shell microstructure. A rough estimation of the thickness of the shell can be done by assuming: (i) a spherical geometry of the particle; (ii) that the crystallographic cells of the core in one hand and of the shell in the other hand are identical which implies that volume and molar ratios of the core and the shell are identical. With this assumption, following relationships can be established for $\left([\mathrm{Lu}(\mathrm{cpbOH})]_{\infty}\right)_{1-\mathrm{x}} @\left([\mathrm{Y}(\mathrm{cpbOH})]_{\infty}\right)_{\mathrm{x}}$ : 


$$
\begin{aligned}
& \mathrm{V}_{\text {core }}=\frac{4}{3} \pi \mathrm{r}_{\text {core }}^{3}=\mathrm{k}(1-\mathrm{x}) \\
& \mathrm{V}_{\text {shell }}=\frac{4}{3} \pi\left(\mathrm{r}_{\text {particle }}^{3}-\mathrm{r}_{\text {core }}^{3}\right)=\mathrm{kx}
\end{aligned}
$$

where $V_{\text {core }}$ and $V_{\text {shell }}$ stand for the core and shell volume respectively, $r_{\text {core }}, r_{\text {shell }}$ and $r_{\text {particle }}$ stand for core, shell and particle radii respectively and where $\mathrm{k}$ is a proportionality factor.

Combination of these two relationships leads to:

$$
\mathrm{r}_{\text {core }}=\sqrt[3]{\frac{1}{2}} \mathrm{r}_{\text {particle }}
$$

for $\mathrm{x}=0.5$ that is $\mathrm{r}_{\text {core }}=0.79 \mathrm{r}_{\text {particle }}$ which seems in reasonable agreement with TEM micrograph.

It has previously been shown ${ }^{[51]}$ that, in this system, temperature dependence of the luminescence intensity strongly depends on inter-metallic energy transfer. Solid state emission spectra vs temperature have been recorded between $77 \mathrm{~K}$ and $300 \mathrm{~K}$ for both the molecular alloy $\quad\left[\mathrm{Tb}_{0.5} \mathrm{Eu}_{0.5}(\mathrm{cpbOH})\right]_{\infty} \quad$ and the core-shell $\left([\mathrm{Tb}(\mathrm{cpbOH})]_{\infty}\right)_{0.5} @\left([\mathrm{Eu}(\mathrm{cpbOH})]_{\infty}\right)_{0.5}($ Figure 7). 

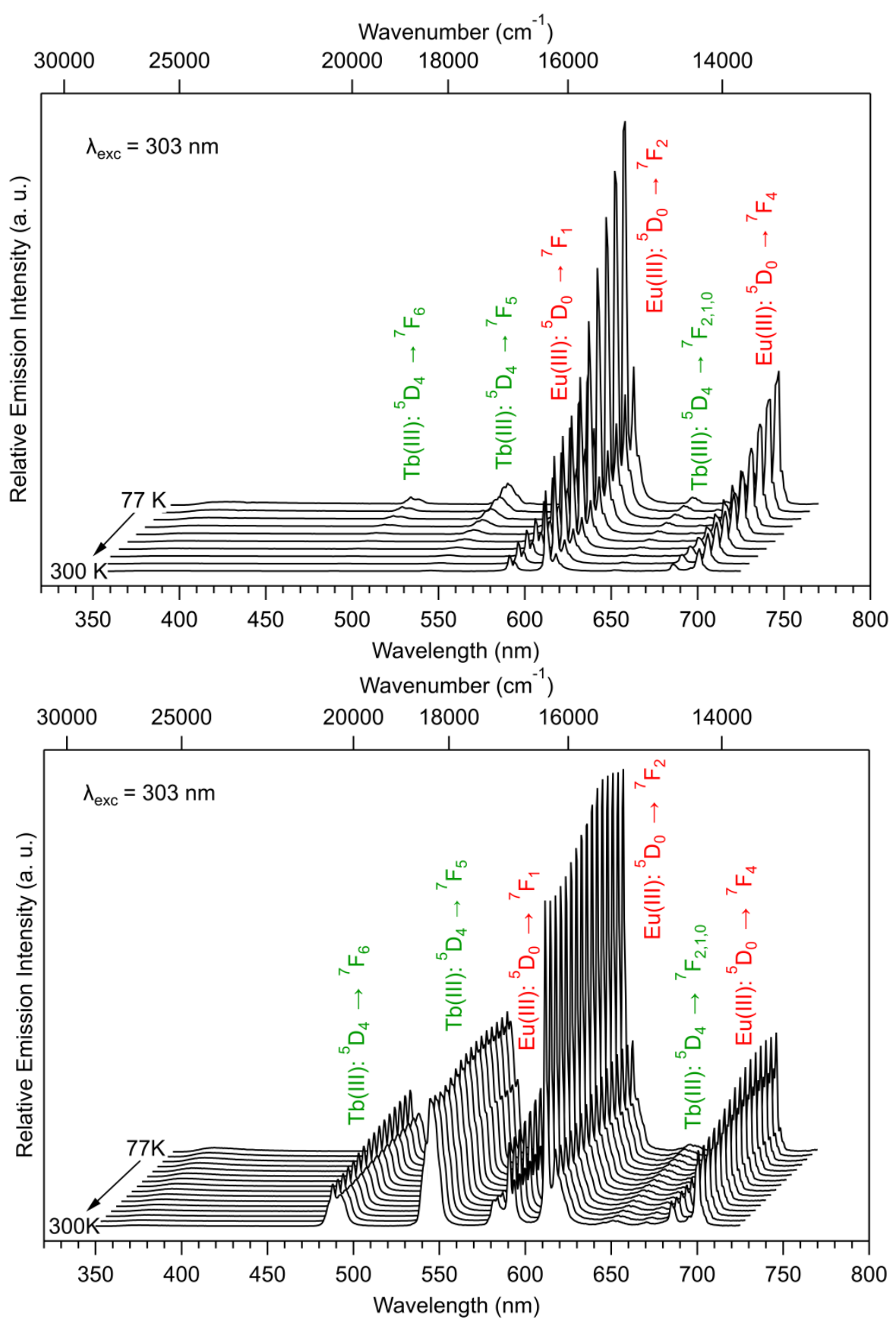

Figure 7. Solid state emission spectra of $\left[\mathrm{Tb}_{0.5} \mathrm{Eu}_{0.5}(\mathrm{cpbOH})\right]_{\infty}$ (top) and $\left([\mathrm{Tb}(\mathrm{cpbOH})]_{\infty}\right)_{0.5} @\left([\mathrm{Eu}(\mathrm{cpbOH})]_{\infty}\right)_{0.5}$ (bottom) between $77 \mathrm{~K}$ and $300 \mathrm{~K}$ upon UV excitation.

This figure clearly shows that luminescence intensities of both $\mathrm{Eu}^{3+}$ and $\mathrm{Tb}^{3+}$ are almost constant over the whole temperature range for the core-shell while they strongly vary for the molecular alloy. $\mathrm{I}_{\mathrm{Tb}} / \mathrm{I}_{\mathrm{Eu}}$ vs $\mathrm{T}$ have been drawn for both compounds where $\mathrm{I}_{\mathrm{Ln}}$ symbolizes integrated intensity of the major emission peak of a $\mathrm{Ln}^{3+}$ ion $\left({ }^{5} \mathrm{D}_{4} \rightarrow{ }^{7} \mathrm{~F}_{5}\right.$ centered 
at $545 \mathrm{~nm}$ for $\mathrm{Tb}^{3+}$ and ${ }^{5} \mathrm{D}_{0} \rightarrow{ }^{7} \mathrm{~F}_{2}$ centered at $612 \mathrm{~nm}$ for $\mathrm{Eu}^{3+}$ ). This figure (Figure 8) confirms that the core-shell microstructure induces a drastic reduction of Tb-to-Eu intermetallic energy transfer. Indeed Figure 8 shows that $\mathrm{I}_{\mathrm{Tb}} / \mathrm{I}_{\mathrm{Eu}}$ strongly decreases as temperature increases for the molecular alloy sample while it remains almost unchanged for the core-shell one. This feature not only highly influences the color of the emission but also its intensity: the core-shell is twice brighter than the molecular alloy (Figure 8). This was expected and fully consistent with the core-shell microstructure. Indeed in the molecular alloy, a significant part of the energy absorbed by $\mathrm{Tb}^{3+}$ ions is transferred to $\mathrm{Eu}^{3+}$ ions that, in this system, present a significantly less bright luminescence than $\mathrm{Tb}^{3+}$ ions do. Therefore the overall brightness of the molecular alloy is reduced. On the contrary in the core-shell sample, intermetallic energy transfers are almost avoided and therefore, the overall brightness is stronger. This property can be of significant interest as far as technological applications are targeted.
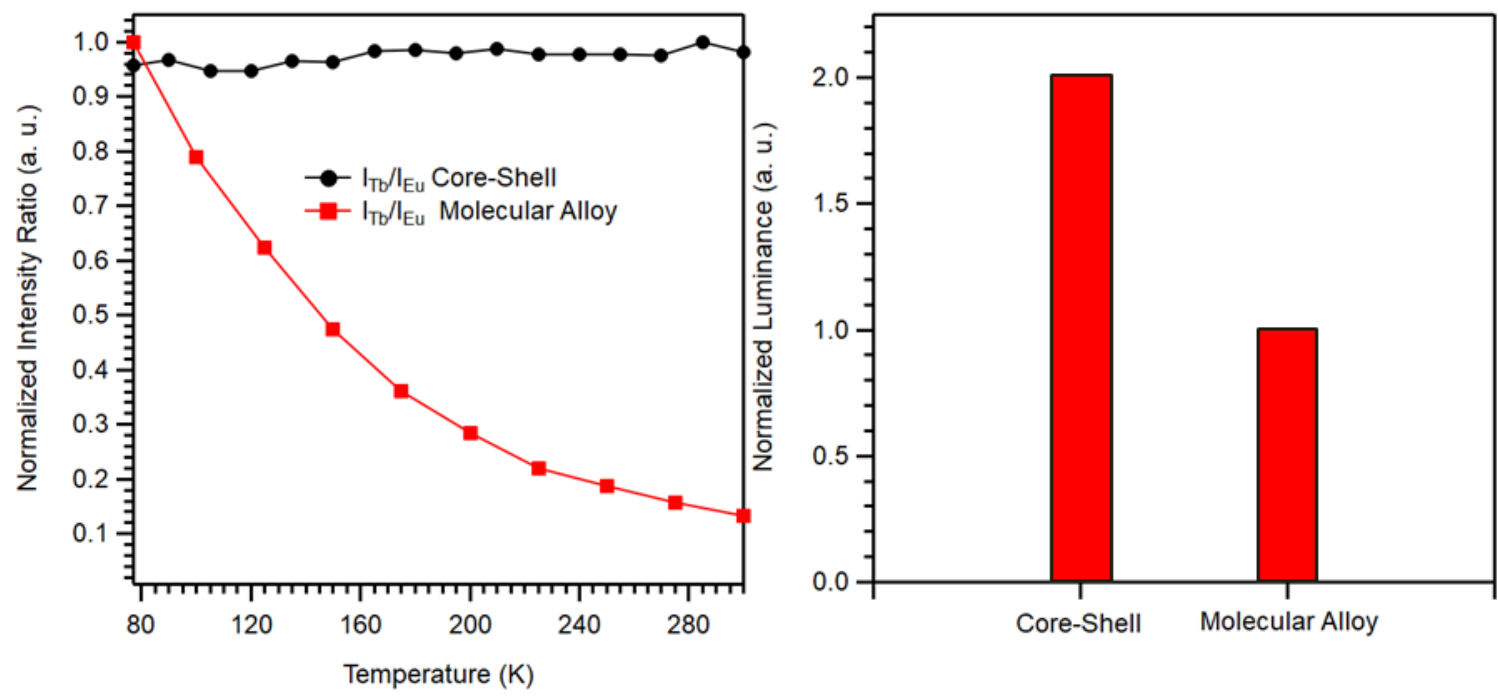

Figure 8. Left: $\mathrm{I}_{\mathrm{Tb}} / \mathrm{I}_{\mathrm{Eu}}$ vs $\mathrm{T}$ have been drawn for $\left([\mathrm{Tb}(\mathrm{cpbOH})]_{\infty}\right)_{0.5} @\left([\mathrm{Eu}(\mathrm{cpbOH})]_{\infty}\right)_{0.5}$ and $\left[\mathrm{Tb}_{0.5} \mathrm{Eu}_{0.5}(\mathrm{cpbOH})\right]_{\infty}\left(\mathrm{I}_{\mathrm{Ln}}\right.$ symbolizes integrated intensity of the major emission peak of a $\mathrm{Ln}^{3+}$ ion $\left({ }^{5} \mathrm{D}_{4} \rightarrow{ }^{7} \mathrm{~F}_{5}\right.$ centered at $545 \mathrm{~nm}$ for $\mathrm{Tb}^{3+}$ and ${ }^{5} \mathrm{D}_{0} \rightarrow{ }^{7} \mathrm{~F}_{2}$ centered at $612 \mathrm{~nm}$ for $\left.\mathrm{Eu}^{3+}\right)$ with $\quad\left(\lambda_{\text {exc }}=303 \mathrm{~nm}\right)$. Right: Normalized luminance of $\left.([\mathrm{Tb}(\mathrm{cpbOH}))]_{\infty}\right)_{0.5} @\left([\mathrm{Eu}(\mathrm{cpbOH})]_{\infty}\right)_{0.5}$ and of $\left[\mathrm{Tb}_{0.5} \mathrm{Eu}_{0.5}(\mathrm{cpbOH})\right]_{\infty}$ under UV irradiation $\left(\lambda_{\text {exc }}=312 \mathrm{~nm}\right)$. 
b) Extension to core-multi-shell particles for optimizing optical insulation: $\left([\mathrm{Tb}(\mathrm{cpbOH})]_{\infty}\right)_{0.25} @\left([\mathrm{Y}(\mathrm{cpbOH})]_{\infty}\right)_{0.1} @\left([\mathrm{Nd}(\mathrm{cpbOH})]_{\infty}\right)_{0.65}$

Synthetic process that has led to core-shell compounds described above is simple and can be easily extended for the preparation of core-multi-shells compounds. In order to verify this assumption we have prepared $\left([\mathrm{Tb}(\mathrm{cpbOH})]_{\infty}\right)_{0.25} @\left([\mathrm{Y}(\mathrm{cpbOH})]_{\infty}\right)_{0.1} @\left([\mathrm{Nd}(\mathrm{cpbOH})]_{\infty}\right)_{0.65}$ compound which has been assumed to be isostructural with $[\mathrm{Tb}(\mathrm{cpbOH})]_{\infty}$ on the basis of its X-ray powder diffraction diagram (Figure S4). Metallic relative contents have been checked by EDS measurements (Table S2). Stoichiometric coefficients (0.25/0.1/0.65) have been calculated (from adapted relationship 3) for providing comparable core radius and outer shell thickness. Y-based inner shell is supposed to fully isolate Tb-based core from Nd-based external shell and therefore to prevent intermetallic energy transfer (Scheme 4).

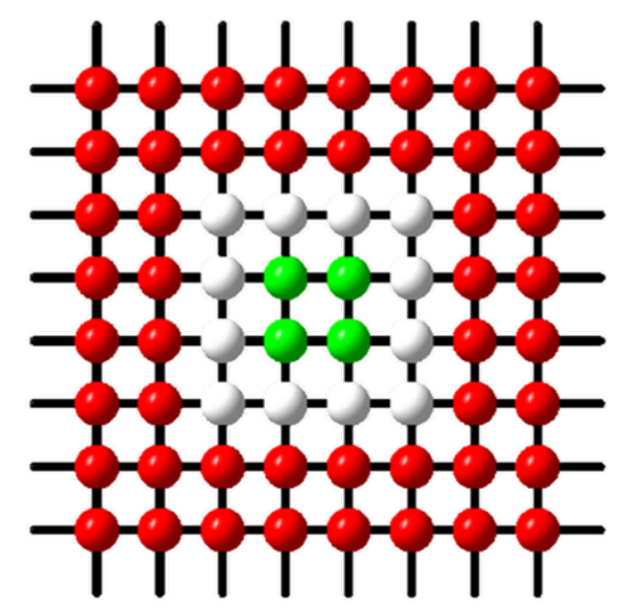

Scheme 4. Schematic representation of a core-multi-shells particle

Emission lifetime of the $\mathrm{Tb}^{3+}$ ions has been measured $\left(\tau_{\mathrm{obs}}(\mathrm{Tb})=0.74(2) \mathrm{ms}\right)$. It is in agreement with the one measured for homo-lanthanide $[\mathrm{Tb}(\mathrm{cpbOH})]_{\infty}(0.83(1) \mathrm{ms})$ which supports the absence of intermetallic energy transfer.

Solid state emission spectra have been recorded at room temperature in both visible and IR regions (Figure 9). 


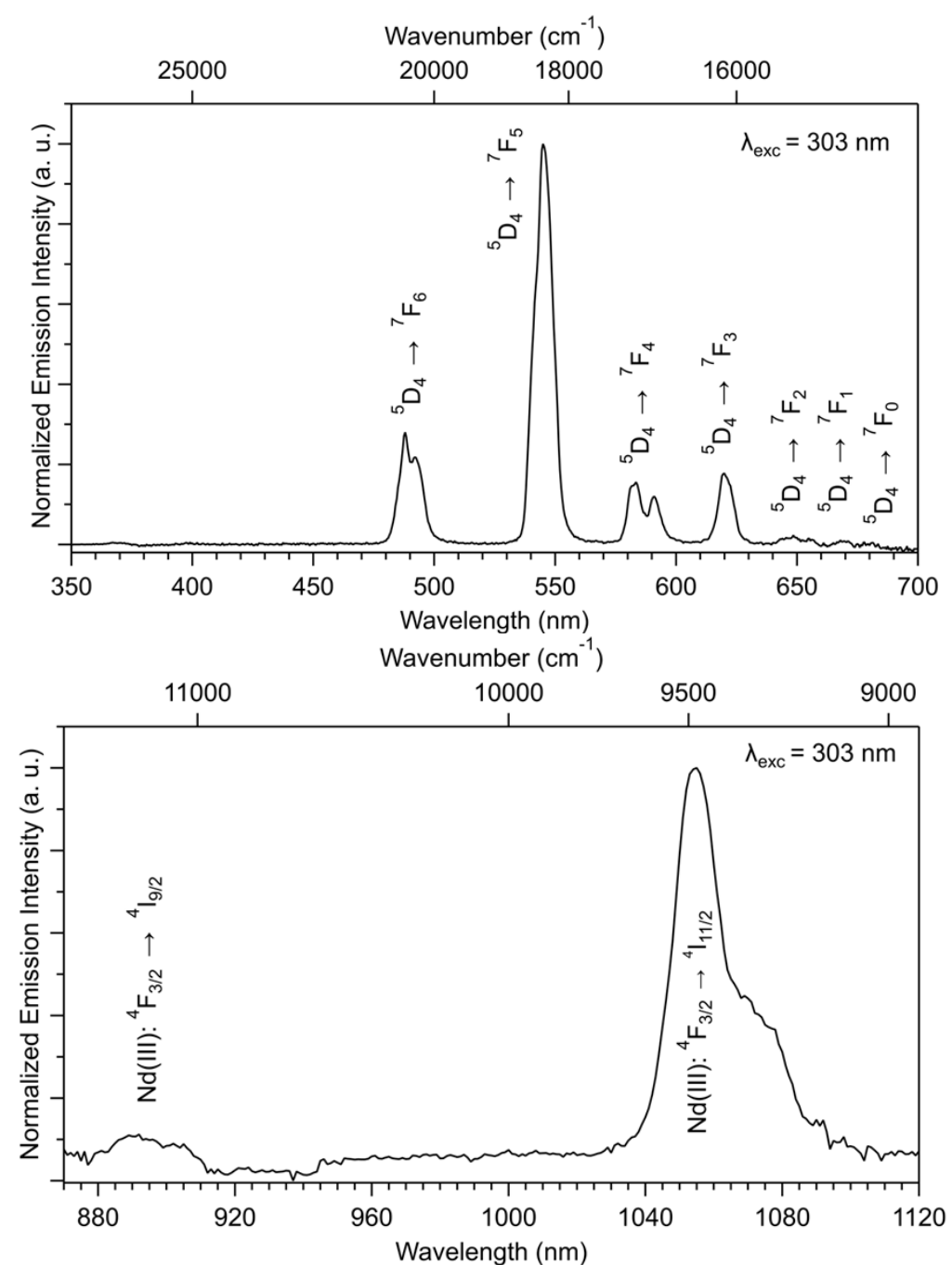

Figure 9. Emission spectra in the visible (top) and IR (bottom) regions of $\left([\mathrm{Tb}(\mathrm{cpbOH})]_{\infty}\right)_{0.25} @\left([\mathrm{Y}(\mathrm{cpbOH})]_{\infty}\right)_{0.1} @\left([\mathrm{Nd}(\mathrm{cpbOH})]_{\infty}\right)_{0.65}$.

This figure shows that in both spectral domains, a quite intense emission is observed under a unique excitation wavelength. This property, although rare, has already been observed for molecular alloys. $^{24,51}$ However, in molecular alloys, dilution by optically inactive lanthanide ions $\left(\mathrm{La}^{3+}, \mathrm{Gd}^{3+}, \mathrm{Y}^{3+}\right.$ or $\left.\mathrm{Lu}^{3+}\right)$ is necessary, which diminishes the useful optically active lanthanide ions contents. With core-shell structured lanthanide based-coordination polymers this drawback can be avoided. Additionally, it can be noticed that measured luminescent lifetime of the $\mathrm{Tb}^{3+}$ ions for this compound is exactly the same than the one measured for $\left([\mathrm{Tb}(\mathrm{cpbOH})]_{\infty}\right)_{0.5} @\left([\mathrm{Eu}(\mathrm{cpbOH})]_{\infty}\right)_{0.5}$ which suggests that introduction of an insulation shell is not mandatory. 


\section{c) A robust concept. Generalization to other systems: $\left(\left[\mathrm{Tb}_{2}(\mathrm{bdc})_{3}\right]_{\infty}\right)_{0.5} @\left(\left[\mathrm{Eu}_{2}(\mathrm{bdc})_{3}\right]_{\infty}\right)_{0.5}$}

In order to confirm the general character of this 3D molecular epitaxial growth we have prepared two samples with the same chemical compositions (Table S2): the molecular alloy $\left[\mathrm{TbEu}(\mathrm{bdc})_{3}\left(\mathrm{H}_{2} \mathrm{O}\right)_{4}\right]_{\infty}$ (hereafter abbreviated as $\left.\left[\mathrm{TbEu}(\mathrm{bdc})_{3}\right]_{\infty}\right)$ and the corresponding core-shell $\left(\left[\mathrm{Tb}_{2}(\mathrm{bdc})_{3}\right]_{\infty}\right)_{0.5} @\left(\left[\mathrm{Eu}_{2}(\mathrm{bdc})_{3}\right]_{\infty}\right)_{0.5}$ where bdc $^{2-}$ stands for 1,4-benzenedicarboxylate. They have been assumed to be isostructural to $\left[\mathrm{Tb}_{2}(\mathrm{bdc})_{3}\left(\mathrm{H}_{2} \mathrm{O}\right)_{4}\right]_{\infty}{ }^{66}$ on the basis of their powder X-ray diffraction patterns (Figure S5). This series of isostructural compounds has been chosen because its 3D crystal structure (Figure 10) is very compact and stable $^{67}$ and because luminescent properties of molecular alloys based on terephthalate have been extensively studied. ${ }^{68-76}$

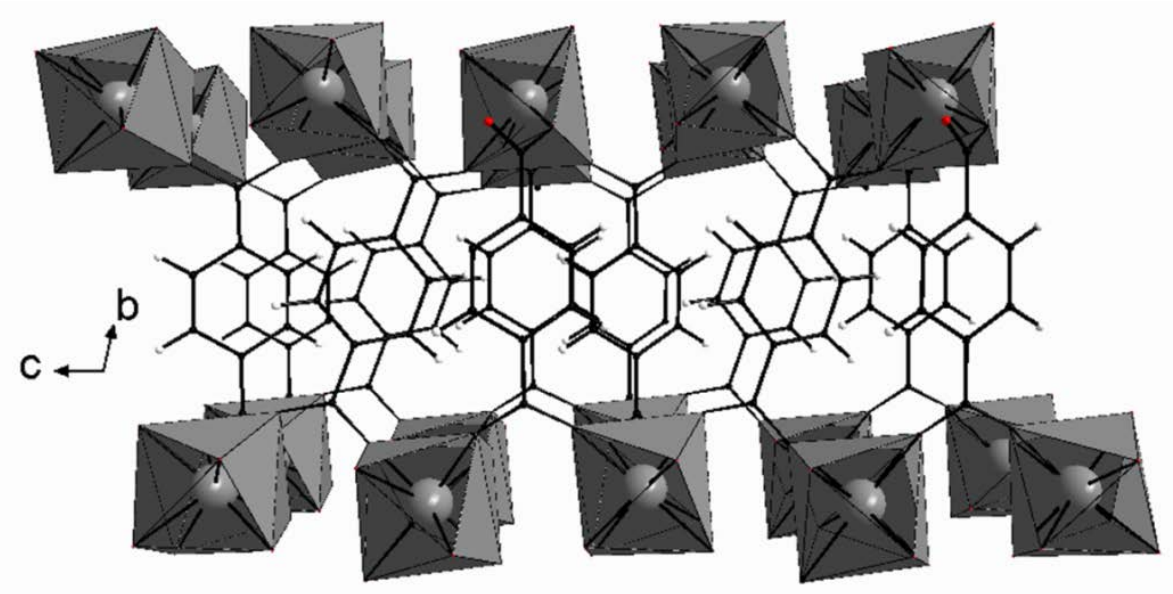

Figure 10. Perspective view along the $a$ axis of the crystal packing of $\left[\mathrm{Tb}_{2}(\mathrm{bdc})_{3}\right]_{\infty}$. Redrawn from reference 66 .

Emission spectra as well as luminescence lifetimes of $\mathrm{Eu}^{3+}$ and $\mathrm{Tb}^{3+}$ ions have been measured for both compounds at room-temperature (Figure 11). As expected, these spectra show a sizeable luminescence intensity of $\mathrm{Tb}^{3+}$ ions for the core-shell sample (see for example, intensity of the ${ }^{5} \mathrm{D}_{4} \rightarrow{ }^{5} \mathrm{~F}_{5}$ transition of $\mathrm{Tb}^{3+}$ centered at $545 \mathrm{~nm}$ ) but almost no luminescence for the molecular alloy. This is mainly due to the efficient intermetallic energy transfer in this latter compound. 
Luminescence lifetimes measurements also stress the drastic differences between molecular alloy and core-shell compound. As expected, $\mathrm{Eu}^{3+}$ lifetimes are identical in both compounds ( $\left.\tau_{\mathrm{Eu}}=0.46(2) \mathrm{ms}\right)$ and in the homo-nuclear coordination polymer $\left(\tau_{\mathrm{Eu}}=0.47(2) \mathrm{ms}^{72}\right)$. However, when looking at the $\mathrm{Tb}^{3+}$ ion, that may present inter-metallic energy transfer toward $\mathrm{Eu}^{3+}$ ion, significant differences are seen: If $\mathrm{Tb}^{3+}$ luminescence lifetime in the core-shell compound $\left(\tau_{\mathrm{Tb}}=0.82(4) \mathrm{ms}\right)$ is close to the one recorded for the Tbbased homo-nuclear compound $\left(\tau_{\mathrm{Tb}}=1.04(3) \mathrm{ms}^{72}\right)$, it is drastically different from the one measured in the molecular alloy $\left(\tau_{\mathrm{Tb}}=0.052(1) \mathrm{ms}\right)$ as very efficient inter-metallic energy transfer diminishes $\tau_{\mathrm{Tb}}$. This supports that inter-metallic energy transfer is very efficient in the molecular alloy sample and almost absent in the core shell one. 

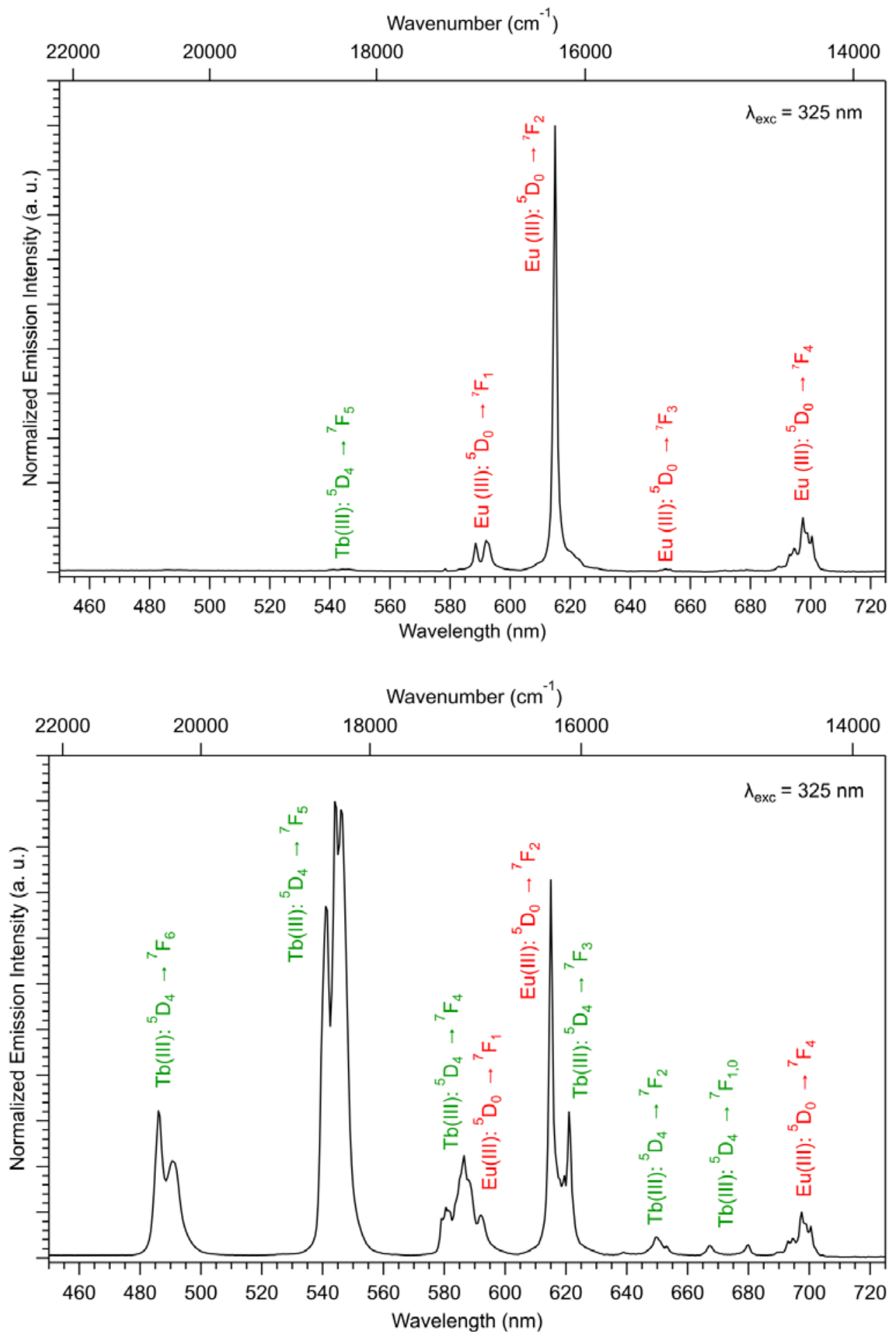

Figure 11. Top: Emission spectrum of $\left[\mathrm{TbEu}(\mathrm{bdc})_{3}\right]_{\infty} \tau_{\mathrm{Tb}}=0.052(1) \mathrm{ms}$ and $\tau_{\mathrm{Eu}}=0.46(1) \mathrm{ms}$. Bottom: Emission spectrum of $\left(\left[\mathrm{Tb}_{2}(\mathrm{bdc})_{3}\right]_{\infty}\right)_{0.5} @\left(\left[\mathrm{Eu}_{2}(\mathrm{bdc})_{3}\right]_{\infty}\right)_{0.5} \cdot \tau_{\mathrm{Tb}}=0.82(4) \mathrm{ms}$ and $\tau_{\mathrm{Eu}}=0.46(2) \mathrm{ms}$.

Additionally, luminance has been measured for both samples (Figure S6). Core-shell sample luminance is $90(1) \mathrm{cd} \cdot \mathrm{m}^{-2}$ while that of the molecular alloy sample is only 
22(1) cd.m ${ }^{-2}$. Again, for this series core-shell microstructure induces a drastic enhancement (four times) of the luminescence intensity.

It has been shown that dilution of the optically active lanthanide ions by optically non-active ones provokes in this series an enhancement of the luminance of about $25 \%{ }^{21}$ Therefore, it must be possible to enhance even more the luminance by preparing core-shell samples in which the core and the shell would be molecular alloys with optimized compositions (Scheme 5).

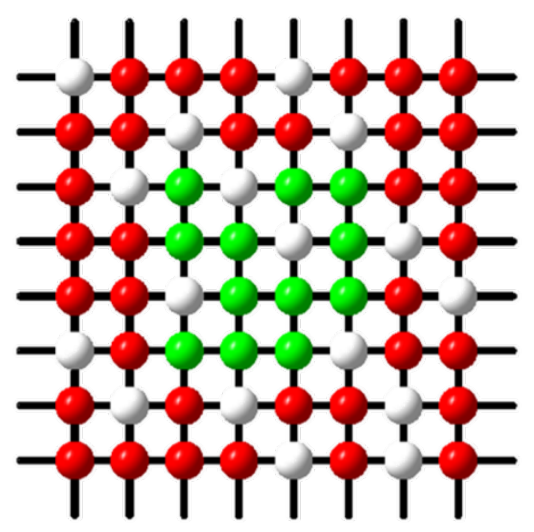

Scheme 5. Schematic representation of a core-shell particle in which the core and the shell are molecular alloys have optimized compositions. Optically non-active lanthanide ions are symbolized by white balls

\section{d) Interest of core-shell particles for crystallo-chemistry: crystal structure induced by}

\section{core germination.}

Core-shells particles are not only useful for improving luminescence efficiency. In solid state chemistry, epitaxial growth is used for imposing a given crystal structure that could not be obtained otherwise. The question is: does it works with 3D molecular epitaxial growth?

To answer this question we have considered lanthanide-based coordination polymers that involve trimesic acid as ligand. This very versatile system has been widely studied. ${ }^{77-83}$ At room-temperature and ambient pressure, reaction in water between a lanthanide ion and the tri-sodium salt of trimesic acid is highly dependent on the lanthanide ion that is considered (Table 2). 
Table 2. Projection views of the crystal structures of lanthanide-based coordination polymers synthesized at room-temperature and ambient pressure with trimesic acid as ligand versus the lanthanide ion that is involved. Redrawn from references 52, 83

\section{$\mathrm{La}-\mathrm{Tb}$}

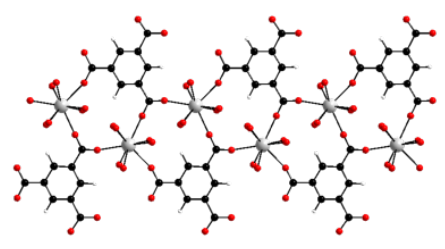

$\left[\operatorname{Ln}(\operatorname{tma})\left(\mathrm{H}_{2} \mathrm{O}\right)_{6}\right]_{\infty}$

Monoclinic system

Space group: $C c\left(n^{\circ} 9\right)$

$a=11.372(2) \AA$

$b=17.850(3) \AA$

$c=7.130(1) \AA$

$\beta=119.14(3)^{\circ}$

CCDC-101660
Dy

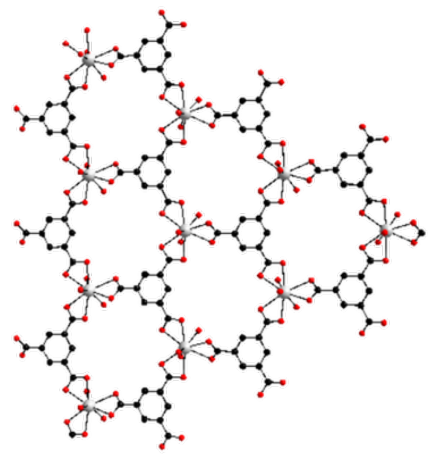

$\left[\operatorname{Ln}(\operatorname{tma})\left(\mathrm{H}_{2} 0\right)_{3} \cdot 1.5 \mathrm{H}_{2} \mathrm{O}\right]_{\infty}$

Monoclinic system

Space group: $C 2 / c\left(n^{\circ} 15\right)$

$a=20.454(2) \AA$

$b=9.973(1) \AA$

$c=15.251(2) \AA$

$\beta=125.68(1)^{\circ}$

CCDC-1102119
$\mathrm{Ho}-\mathrm{Yb}$

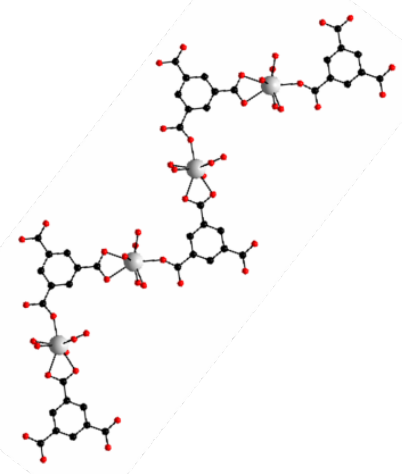

$\left[\operatorname{Ln}(\operatorname{tma})\left(\mathrm{H}_{2} \mathrm{O}\right)_{5} \cdot 3.5 \mathrm{H}_{2} \mathrm{O}\right]_{\infty}$

Monoclinic system

Space group: $\mathrm{C} 2 / \mathrm{c}\left(\mathrm{n}^{\circ} 15\right)$

$a=14.7396(15) \AA$

$b=16.9874(15) \AA$

$c=14.4591(14) \AA$

$\beta=118.754(9)^{\circ}$

CCDC-101659

Crystal structure of the Dy-based compound is 2D while that of the Tb-based compound is 1D. In order to confirm that this method is really a 3D epitaxial growth, we have prepared and compared three compounds: The two homo-lanthanide coordination polymers $\left[\mathrm{Tb}(\mathrm{tma})\left(\mathrm{H}_{2} \mathrm{O}\right)_{6}\right]_{\infty} \quad$ and $\quad\left[\mathrm{Dy}(\mathrm{tma})\left(\mathrm{H}_{2} \mathrm{O}\right)_{3} \cdot 1.5 \mathrm{H}_{2} \mathrm{O}\right]_{\infty}$, and the core-shell $\left[\mathrm{Tb}(\mathrm{tma})\left(\mathrm{H}_{2} \mathrm{O}\right)_{6}\right]_{\infty} @\left[\mathrm{Dy}(\mathrm{tma})\left(\mathrm{H}_{2} \mathrm{O}\right)_{6}\right]_{\infty}$ (Figure 12). Relative metallic contents have been checked by EDS measurements (Table S2). SEM Pictures reported in Figure 12 show that core-shell particles present a needle-like morphology, as the Tb-based homo-lanthanide particles. Once more, it appears that core-shell particles are bigger than homo-lanthanide ones which supports the assumption that cores act as crystallization nuclei. 

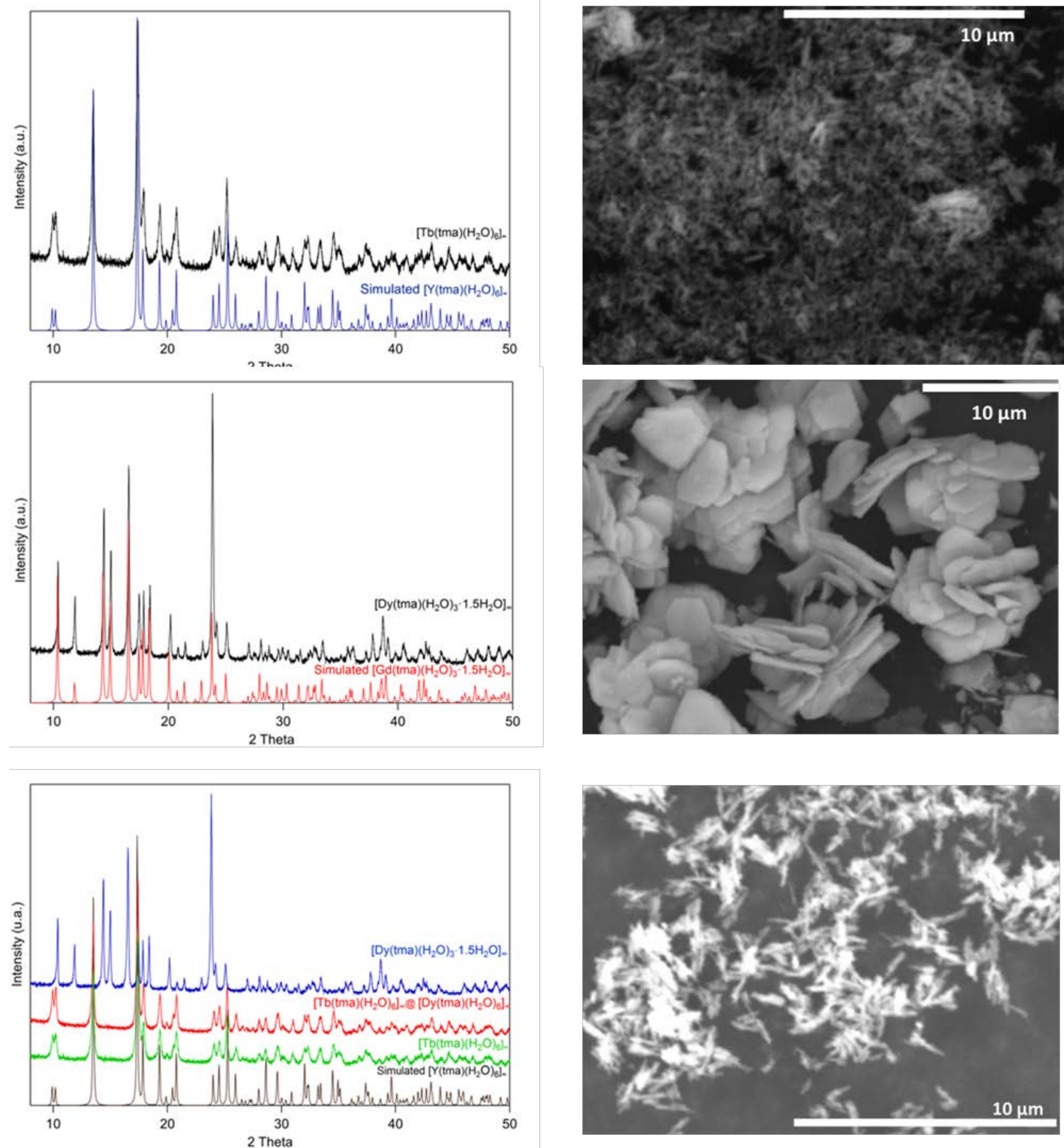

Figure 12. Experimental and simulated powder X-ray diffraction diagrams (left) and SEM pictures of the microcrystalline powders (right from top to bottom) of $\left[\mathrm{Tb}(\mathrm{tma})\left(\mathrm{H}_{2} \mathrm{O}\right)_{6}\right]_{\infty}$, $\left[\mathrm{Dy}(\mathrm{tma})\left(\mathrm{H}_{2} \mathrm{O}\right)_{3} \cdot 1.5 \mathrm{H}_{2} \mathrm{O}\right]_{\infty}$ and $\left[\mathrm{Tb}(\mathrm{tma})\left(\mathrm{H}_{2} \mathrm{O}\right)_{6}\right]_{\infty} @\left[\mathrm{Dy}(\mathrm{tma})\left(\mathrm{H}_{2} \mathrm{O}\right)_{6}\right]_{\infty}$.

Figure 12 evidences that the Tb-based core imposes its crystal structure to the Dy-based shell. This feature can be of particular interest because it makes possible the preparation of micro-crystalline powders that don't exist otherwise. One can imagine, for instance, an optically non-active core that would impose its crystal structure to an optically active shell with original optical properties. 
However, it must be kept in mind that $3 \mathrm{D}$ epitaxial growth is limited by the relative strengths of the different equilibria that exist in solution. For instance, in the present case, it is impossible to generate $\left[\mathrm{Dy}(\mathrm{tma})\left(\mathrm{H}_{2} 0\right)_{3} \cdot 1.5 \mathrm{H}_{2} \mathrm{O}\right]_{\infty} @\left[\mathrm{~Tb}(\mathrm{tma})\left(\mathrm{H}_{2} 0\right)_{3} \cdot 1.5 \mathrm{H}_{2} \mathrm{O}\right]_{\infty}$ in which a Dy-based core would impose its crystal structure to a Tb-based shell. This could be related to previous works that showed that, for isolated complexes, the selective introduction of different lanthanide ions is only possible upon kinetic control. ${ }^{84-86}$ To the best of our knowledge no equivalent study has been reported so far for coordination polymers.

\section{CONCLUSIONS AND OUTLOKS.}

In this paper, it is shown that lanthanide-based coordination compounds are ideal candidates for 3D molecular epitaxial growth, because of their intrinsic chemical properties. Of course, this technic requires to be optimized and numerous key points remain to improve. However, we are firmly convinced that core-shell micro-structuration will make possible the preparation of new materials with unprecedented physical properties. Indeed, this opens the way to the preparation of multi-emissive luminescent materials with enhanced luminescence intensities. This also opens the way to original multi-functional materials. For example, one can imagine a core-shell in which one shell could be devoted to magnetic properties and another one to optical properties. Because of the absence of inter-metallic energy transfer, both properties could co-exist in a same particle.

At last, this technic makes possible the preparation of new compounds that are impossible to synthesize otherwise.

\section{ACKNOWLEDGEMENTS}

TEM experiments were performed on THEMIS platform (ScanMAT, UMS 2011 University of Rennes 1-CNRS; CPER-FEDER 2007-2014). 


\section{SUPPORTING INFORMATION}

Refined cell parameters for $[\operatorname{Ln}(\mathrm{cpbOH})]_{\infty}(\operatorname{Ln}=\operatorname{Pr}$ to Lu, plus Y); Metallic contents measured by EDS; Luminescence decay curves for $\mathrm{Tb}(\mathrm{cpbOH})]_{\infty},[\mathrm{Eu}(\mathrm{cpbOH})]_{\infty}$, $\left[\mathrm{Tb}_{0.5} \mathrm{Eu}_{0.5}(\mathrm{cpbOH})\right]_{\infty}$ and $\left([\mathrm{Tb}(\mathrm{cpbOH})]_{\infty}\right)_{0.5} @\left([\mathrm{Eu}(\mathrm{cpbOH})]_{\infty}\right)_{0.5}$; Overall EDS spectrum of $\left([\mathrm{Lu}(\mathrm{cpbOH})]_{\infty}\right)_{0.5} @\left([\mathrm{Y}(\mathrm{cpbOH})]_{\infty}\right)_{0.5}$; Experimental powder X-ray diffraction diagram of $\left([\mathrm{Lu}(\mathrm{cpbOH})]_{\infty}\right)_{0.5} @\left([\mathrm{Y}(\mathrm{cpbOH})]_{\infty}\right)_{0.5}$. Simulated from its crystal structure powder X-ray diffraction diagram of $[\mathrm{Tb}(\mathrm{cpbOH})]_{\infty}$; Experimental powder X-ray diffraction of $\left([\mathrm{Tb}(\mathrm{cpbOH})]_{\infty}\right)_{0.25} @\left([\mathrm{Y}(\mathrm{cpbOH})]_{\infty}\right)_{0.1} @\left([\mathrm{Nd}(\mathrm{cpbOH})]_{\infty}\right)_{0.65} ; \quad$ Experimental powder X-ray diffraction of $\left(\left[\mathrm{Tb}_{2}(\mathrm{bdc})_{3}\right]_{\infty}\right)_{0.5} @\left(\left[\mathrm{Eu}_{2}(\mathrm{bdc})_{3}\right]_{\infty}\right)_{0.5} ;$ Normalized luminance of $\left[\mathrm{Tb}_{2}(\mathrm{bdc})_{3}\right]_{\infty}$ (reference), $\left(\left[\mathrm{Tb}_{2}(\mathrm{bdc})_{3}\right]_{\infty}\right)_{0.5} @\left(\left[\mathrm{Eu}_{2}(\mathrm{bdc})_{3}\right]_{\infty}\right)_{0.5}$ (core-shell) and $\left[\mathrm{TbEu}(\mathrm{bdc})_{3}\right]_{\infty}$ (molecular alloy). 


\section{REFERENCES}

1. Cui, Y.; Li, B.; He, H.; Zhou, W.; Chen, B.; Qian, G., Metal-organic frameworks as platforms for functionnal materials. Accounts Chem. Res. 2016, 49, 483-493.

2. Li, X.-Y.; Shi, W.-J.; Wang, X.-Q.; Ma, L.-N.; Hou, L.; Wang, Y.-Y., Luminescence modulation, white light emission and energy transfer in a family of lanthanide Metal-Organic Frameworks based on a planar $\pi$-conjugated ligand. Cryst. Growth Des. 2017, 17, 4217-4224.

3. You, H.; Fang, J.; Xuan, Y.; Ma, D., Highly efficient red electroluminescence from stacked organic light emitting devices based on europium complexes. Mater. Sci. Eng. B 2006, 131, 252-255.

4. Binnemans, K., Lanthanide based luminescent hybrid materials. Chem. Rev. 2009, 109, 42834374.

5. Bünzli, J. C. G., Rising stars in science and technology : Luminescent lanthanide materials. Eur. J. Inorg. Chem. 2017, 5058-5063.

6. Comby, S.; Bünzli, J. C. G.; Gschneider, K. A.; Pecharsky, V. K., Lanthanide Near-Infrared Luminescence in Molecular Probes and Devices. In Handbook on the Physics and Chemistry of Rare Earths, Elsevier: Amsterdam, 2007; Vol. 37, pp 1-353.

7. Bünzli, J.-C. G., Lanthanide luminescence for biomedical analyses and imaging. Chem. Rev. 2010, 111, 2729-2755.

8. Dang, S.; Min, X.; Yang, W.; Yi, F. Y.; You, H.; Sun, Z. M., Lanthanide metal-organic frameworks showing luminescence in the visible and near infrared regions with potential for acetone sensing. Chem. - Eur. J. 2013, 19, 17172-17179.

9. Rao, X.; Song, T.; Gao, J.; Cui, Y.; Yang, Y.; Wu, C.; Chen, B.; Qian, G., A highly sensitive mixed lanthanide metal organic framework self calibrated luminescent thermometer. J. Am. Chem. Soc. 2013, 135, 15559-15564.

10. Cui, Y.; Xu, H.; Yue, Y.; Guo, Z.; Yu, J.; Chen, Z.; Gao, J.; Yang, Y.; Qian, G.; Chen, B., A Luminescent Mixed-Lanthanide Metal-Organic Framework Thermometer. J. Am. Chem. Soc. 2012, 134, 3979-3982.

11. Rocha, J.; Brites, D. S. C.; Carlos, L. D., Lanthanide organic framework luminescent thermometers. Chem. - Eur. J. 2016, 22, 14782-14795.

12. Guillou, O.; Daiguebonne, C.; Calvez, G.; Bernot, K., A long journey in lanthanide chemistry : from fundamental crystallogenesis studies to commercial anti-counterfeiting taggants. Accounts Chem. Res. 2016, 49, 844-856.

13. Andres, J.; Hersch, R. D.; Moser, J. E.; Chauvin, A. S., A new counterfeiting feature relying on invisible luminescent full color images printed with lanthanide-based Inks. Adv. Func. Mater. 2014, 24, 5029-5036.

14. White, K. A.; Chengelis, D. A.; Gogick, K. A.; Stehman, J.; Rosi, N. L.; Petoud, S., Near infra-red luminescent lanthanide MOF barcodes. J. Am. Chem. Soc. 2009, 131, 18069-18071.

15. Qi, Q.; Li, C.; Liu, X.; Jiang, S.; Xu, Z.; Lee, R.; Zhu, M.; Xu, B.; Tian, W., Solid-state photoinduced luminescence swithfor advanced anticounterfeiting and super-resolution imaging. J. Am. Chem. Soc. 2017, 139, 16036-16039.

16. Gooch, J.; Daniel, B.; Abbate, V.; Frascione, N., Taggant materials in forensic science. Trends Anal. Chem. 2016, 83, 49-54.

17. Karraker, D. G., Coordination of trivalent lanthanide ions. J. Chem. Educ. 1970, 47, 424-430.

18. Desreux, J. F., In Lanthanide Probes in Life, Chemical and Earth Sciences, Choppin, G. R.; Bünzli, J. C. G., Eds. Elsevier: Amsterdam, 1989; Vol. Elsevier, p 43.

19. Zhou, D.; Huang, C.; Wang, K.; Xu, G., Synthesis, characterization, crystal structure and luminescent property studies on a novel heteronuclear lanthanide complex $\left.\left\{\mathrm{H}_{[} \mathrm{EuLa}_{2}(\mathrm{DPA})_{5} .8 \mathrm{H}_{2} \mathrm{O}\right] .8 \mathrm{H}_{2} \mathrm{O}\right\}_{\mathrm{n}}\left(\mathrm{H}_{2} \mathrm{DPA}=\right.$ pyridine-2,6-dicarboxylic acid). Polyhedron 1994, 13, 987-991.

20. Fan, X.; Freslon, S.; Daiguebonne, C.; Calvez, G.; Le Polles, L.; Bernot, K.; Guillou, O., Heteronuclear lanthanide-based coordination polymers exhibiting tunable multiple emission spectra. J. Mater. Chem. C 2014, 5510-5525. 
21. Haquin, V.; Etienne, M.; Daiguebonne, C.; Freslon, S.; Calvez, G.; Bernot, K.; Le Polles, L.; Ashbrook, S. E.; Mitchell, M. R.; Bünzli, J. C. G.; Guillou, O., Color and Brightness tuning in heteronuclear lanthanide teraphthalate coordination polymers. Eur. J. Inorg. Chem. 2013, 3464-3476.

22. Le Natur, F.; Calvez, G.; Daiguebonne, C.; Guillou, O.; Bernot, K.; Ledoux, J.; Le Polles, L.; Roiland, C., Coordination polymers based on hexanuclear rare earth complexes : Toward independant luminescence brightness and color emission. Inorg. Chem. 2013, 52, 6720-6730.

23. Dechambenoit, P.; Ferlay, S.; Kyritsakas, N.; Hosseini, M. W., Playing with isostructurality : from tectons to molecular alloys and composite crystals. Chem. Comm. 2009, 1559-1561.

24. Badiane, A. M.; Freslon, S.; Daiguebonne, C.; Suffren, Y.; Bernot, K.; Calvez, G.; Costuas, K.; Camara, M.; Guillou, O., Lanthanide based coordination polymers with a 4,5-dichlorophthalate ligand exhibiting highly tunable luminescence : Toward luminescent bar codes. Inorg. Chem. 2018, 57, 33993410.

25. Badiane, I.; Freslon, S.; Suffren, Y.; Daiguebonne, C.; Calvez, G.; Bernot, K.; Camara, M.; Guillou, O., High britness and easy color modulation in lanthanide-based coordination polymers with 5-methoxyisophthalate as ligand: Toward emission colors additive strategy. Cryst. Growth Des. 2017, $17,1224-1234$.

26. Freslon, S.; Luo, Y.; Daiguebonne, C.; Calvez, G.; Bernot, K.; Guillou, O., Brightness and color tuning in a series of lanthanide-based coordination polymers with benzene 1,2,4,5-tetracarboxylic acid as ligand. Inorg. Chem. 2016, 55, 794-802.

27. Freslon, S.; Luo, Y.; Calvez, G.; Daiguebonne, C.; Guillou, O.; Bernot, K.; Michel, V.; Fan, X., Influence of photo-induced electron transfer on lanthanide-based coordination polymers luminescence : A comparison between two pseudo-isoreticular molecular networks. Inorg. Chem. 2014, 53, 1217-1228.

28. Luo, Y.; Zheng, Y.; Calvez, G.; Freslon, S.; Bernot, K.; Daiguebonne, C.; Roisnel, T.; Guillou, O., Synthesis, Crystal Structure and Luminescent Properties of New Lanthanide-Containing Coordination Polymers Involving 4,4'-oxy-bis-benzoate as Ligand. Cryst. Eng. Comm. 2013, 15, 706-720.

29. Kerbellec, N.; Kustaryono, D.; Haquin, V.; Etienne, M.; Daiguebonne, C.; Guillou, O., An Unprecedented Family of Lanthanide-Containing Coordination Polymers with Highly Tunable Emission Properties. Inorg. Chem. 2009, 48, 2837-2843.

30. Lekshmi, S. S.; Ramya, A. R.; Reddy, M. L. P.; Varughese, S., Lanthanide complex-derived white-light emitting solids: A survey on design strategies. J. Photochem. Photobiol. C 2017, 33, 109131.

31. Einkauf, J. D.; Kelley, T. T.; Chan, B. C.; de Lill, D. T., Rethinking Sensitized Luminescence in Lanthanide Coordination Polymers and MOFs: Band Sensitization and Water Enhanced Eu Luminescence in [ $\mathrm{Ln}(\mathrm{C} 15 \mathrm{H} 905) 3(\mathrm{H} 2 \mathrm{O}) 3] \mathrm{n}(\mathrm{Ln}=\mathrm{Eu}, \mathrm{Tb})$. Inorg. Chem. 2016, 55, 7920-7927.

32. Einkauf, J. D.; Clark, J. M.; Paulive, A.; Tanner, G. P.; De Lill, D. T., A General Model of Sensitized Luminescence in Lanthanide-Based Coordination Polymers and Metal-Organic Framework Materials. Inorg. Chem. 2017, 56, 5544-5552.

33. De Lill, D. T.; De Bettancourt-Dias, A.; Cahill, C. L., Exploring lanthanide luminescence in metal-organic framework : synthesis, structure, and guest-sensitized luminescence of a mixed europium/terbium-adipate framework and a terbium-adipate framework. Inorg. Chem. 2007, 46, 3960-3965.

34. Daiguebonne, C.; Guillou, O.; Kerbellec, N. Procédéde marquage de matériaux à base de matrices organiques polymériques thermoplastiques ou thermodurcissables. FR07/04024, 2007.

35. Daiguebonne, C.; Guillou, O.; Kerbellec, N. Procédé de marquage d'un matériau comprenant au moins une matrice minérale et matériau correspondant. FR2906393, 21sept06, 2006.

36. Steed, J. W.; Goeta, A. E.; Lipkowski, J.; Swierczynski, D.; Panteleon, V.; Handa, S., Templated crystal nucleation : mixed crystals of very different copper(II) N,N',N"-trimethyltriazacyclononane complexes. Chem. Comm. 2007, 813-815.

37. Balogh, C. M.; Veyre, L.; Pilet, G.; Charles, C.; Viriot, L.; Andraud, C.; Thieuleux, C.; Riobé, F.; Maury, O., Two-color three states luminescent lanthanide core-shell crystals. Chem. - Eur. J. 2017, 23, 1784-1788. 
38. Zhang, F.; Adolf, C. R. R.; Zigon, N.; Ferlay, S.; Kyritsakas, N.; Hosseini, M. W., Molecular tectonics : hierarchical organization of heterobimetallic coordination networks into heterotrimetallic core-shell crystals. Chem. Comm. 2017, 53, 3587-3590.

39. Wang, L.; Yang, W.; Li, Y.; Xie, Z.; Zhu, W.; Sun, Z.-M., Dynamically controlled one-pot synthesis of heterogenous core-shell MOF single crystals using guest molecules. Chem. Comm. 2014, 50, 11653-11656.

40. Catala, L.; Brinzei, D.; Prado, Y.; Gloter, A.; Stéphan, O.; Rogez, G.; Mallah, T., Core-multishell magnetic coordination nanoparticles: Toward multifunctionality on the nanoscale. Angew. Chem. Int. Ed. 2009, 48, 183-187.

41. Fukushima, T.; Horike, S.; Kobayashi, H.; Tsujimoto, M.; Isoda, S.; Foo, M. L.; Kubota, Y.; Takata, M.; Kitagawa, S., Modular design of domain assembly in porous coordination polymer crystals via reactivity-directed crystallization process. J. Am. Chem. Soc. 2012, 134, 13341-13347.

42. Furukawa, S.; Hirai, K.; Nakagawa, K.; Takashima, Y.; Matsuda, R.; Tsuruoka, T.; Kondo, M.; Haruki, R.; Tanaka, D.; Sakamoto, H.; Shimomura, S.; Sakata, O.; Kitagawa, S., Heterogeneously hybridized porous coordination polymer crystals : Fabrication of heterometallic core-shell single crystals with an in plane rotational epitaxial relationship. Angew. Chem. Int. Ed. 2009, 48, 1766-1770.

43. Furukawa, S.; Hirai, K.; Takashima, Y.; Nakagawa, K.; Kondo, M.; Tsuruoka, T.; Sakata, O.; Kitagawa, S., A block PCP crystal : anisotropic hybridization of porous coordination polymers by faceselective epitaxial growth. Chem. Comm. 2009, 5097-5099.

44. Koh, K.; Wong-Foy, A. G.; Matzger, A. J., MOF@MOF : microporous core-shell architecture. Chem. Comm. 2009, 6162-6164.

45. Yoo, Y.; Jeong, H.-K., Heteroepitaxial growth of isoreticular Metal-Organic Frameworks and their hybrid films. Cryst. Growth Des. 2010, 10, 1283-1288.

46. Hirai, K.; Chen, K.; Fukushima, T.; Horike, S.; Kondo, M.; Louvain, N.; Kim, C.; Sakata, O.; Meilikhov, M.; sakata, Y.; Kitagawa, S.; Furukawa, S., Programmed crystallization via epitaxial growth and ligand replacement towards hybridizing poruos coordination polymers. Dalton Trans. 2013, 42, 15868-15872.

47. Hirai, K.; Furukawa, S.; Kondo, M.; Meilikhov, M.; Sakata, Y.; Sakata, O.; Kitagawa, S., Targeted functionalization of a hierarchically-structured porous coordination polymer crystal enhances its entire function. Chem. Comm. 2012, 48, 6472-6474.

48. Hirai, K.; Furukawa, S.; Kondo, M.; Hiromitsu, U.; Sakata, O.; Kitagawa, S., Sequential functionnalization of porous coordination polymers. Angew. Chem. Int. Ed. 2011, 50, 8057-8061.

49. da Luz, L. L.; Viana, B. F. L.; da Silva, G. C. O.; Gatto, C. C.; Fontes, A. M.; Malta, M.; Weber, I. T.; Rodrigues, M. O.; Junio, S. A., Controlling the energy transfer in lanthanide-organic frameworks for the production of white-light emitting materials. Cryst. Eng. Comm. 2014, 16, 6914-6918.

50. Cadman, L. K.; Mahon, M. F.; Burrows, A. D., The effect of metal distribution on the luminescence properties of mixed-lanthanide metal-organic frameworks. Dalton Trans. 2018, 47, 2360-2367.

51. Abdallah, A.; Freslon, S.; Fan, X.; Rojo, A.; Daiguebonne, C.; Suffren, Y.; Bernot, K.; Calvez, G.; Roisnel, T.; Guillou, O., Lanthanide based coordination polymers with 1,4 carboxyphenylboronic ligand: multi emissive compounds for multi sensitive luminescent thermometric probes. Inorg. Chem. 2018, 10.1021/acs.inorgchem.8b02681.

52. Daiguebonne, C.; Gérault, Y.; Guillou, O.; Lecerf, A.; Boubekeur, K.; Batail, P.; Kahn, M.; Kahn, O., A new honeycomb-like molecular compound: $\mathrm{Gd}[\mathrm{C} 6 \mathrm{H} 3(\mathrm{COO}) 3](\mathrm{H} 2 \mathrm{O}) 3.1 .5 \mathrm{H} 2 \mathrm{O}$ J. Alloys Compd. 1998, 275-277, 50-53.

53. Deluzet, A.; Maudez, W.; Daiguebonne, C.; Guillou, O., Interplane distances modulation in lanthanide-based coordination polymers. Cryst. Growth Des. 2003, 3, 475-479.

54. Fan, X.; Freslon, S.; Daiguebonne, C.; Le Polles, L.; Calvez, G.; Bernot, K.; Guillou, O., A family of lanthanide based coordination polymers with boronic acid as ligand. Inorg. Chem. 2015, 54, 55345546.

55. Notation : core@shell 
56. Kraus, W.; Nolze, G., POWDER CELL - A program for the representation and manipulation of crystal structures and calculation of the resulting X-ray powder patterns. J. Appl. Crystallogr. 1996, 29, 301-303.

57. Roisnel, T.; Rodriguez-Carjaval, J., A Window Tool for Powder Diffraction Patterns Analysis. J. Mater. Sci. Forum 2001, 378, 118-123.

58. Roisnel, T.; Rodriguez-Carjaval, J., WinPLOTR : a windows tool for powder diffraction pattern analysis. Materials Science Forum, Proceedings of the Seventh European Powder Diffraction Conference (EPDIC 7) 2000, 118-123.

59. Le Bail, A., Monte Carlo Indexing with McMaille. Powder Diffr. 2004, 19, 249-254.

60. Shinley, R. The CRYSFIRE system for automatic powder indexing.

61. CIE, International Commission on Illumination - Technical report. CIE: 1995; Vol. 13-3, p 16.

62. Wyszecki, G., Colorimetry. In Handbook of Optics, Driscoll, W. G.; Vaughan, W., Eds. Mac Graw-Hill Book Company: New-York, 1978, pp 1-15.

63. Weissman, S. I., Intramolecular energy transfer - The fluorescence of complexes of europium. J. Chem Phys 1942, 10, 214-217.

64. Bünzli, J. C. G.; Eliseeva, S. V., Basics of lanthanide photophysics. In Lanthanide Luminescence, Hänninen, P.; Härmä, H., Eds. Springer Berlin Heidelberg: 2010, 10.1007/4243_2010_3pp 1-45.

65. Piguet, C.; Bünzli, J. C. G.; Bernardinelli, G.; Hopfgatner, G.; Williams, A. F., Self-assembly and photophysical properties of lanthanide dinuclear triple-helical complexes. J. Am. Chem. Soc. 1993, 115, 8197-8206.

66. Reneike, T. M.; Eddaoudi, M.; Fehr, M.; Kelley, D.; Yaghi, O. M., From Condensed Lanthanide Coordination Solids to Microporous Frameworks Having Accessible Metal sites. J. Am. Chem. Soc. 1999, 121, 1651-1657.

67. Daiguebonne, C.; Kerbellec, N.; Bernot, K.; Gérault, Y.; Deluzet, A.; Guillou, O., Synthesis, Crystal Structure and Porosity Estimation of Hydrated Erbium Terephtalate Coordination Polymers. Inorg. Chem. 2006, 45, 5399-5406.

68. Zhao, X. J.; Yang, J. H.; Liu, Y.; Gao, P. F.; Li, Y. F., Metal-organic coordination polymers of Tb2$\mathrm{xEux}(\mathrm{bdc}) 3(\mathrm{H} 2 \mathrm{O}) \mathrm{n}$ with tunable fluorescence and smart response toward aldehydes. RSC Advances 2014, 4, 2573-2576.

69. Jin, L.-N.; Liu, Q.; Lu, Y.; Sun, W.-Y., Ultrasonic assisted solution-phase synthesis of gadolinium benzene-1,4-dicarboxylate hierarchical architectures and their sold state thermal transformation. Cryst. Eng. Comm. 2012, 14, 3515-3520.

70. Cadiau, A.; Brites, D. S. C.; Costa, P. M. F. J.; Ferreira, R. A. S.; Rocha, J.; Carlos, L. D., Ratiometric nanomether based on an emissive $\operatorname{Ln}^{3+}$-organic framework. ACS Nano 2013, 7, $7213-$ 7218.

71. Panyarat, K.; Thammakan, S.; Ngamjarurojana, A.; Rujiwatra, A., Ratiometric luminescence behavior of lanthanide-mixed benzenedicarboxylate frameworks. Materials Letters 2018, 213, 166169.

72. Daiguebonne, C.; Kerbellec, N.; Guillou, O.; Bünzli, J. C. G.; Gumy, F.; Catala, L.; Mallah, T.; Audebrand, N.; Gérault, Y.; Bernot, K.; Calvez, G., Structural and luminescent properties of microsized and nano-sized particles of lanthanide terephthalate coordination polymers. Inorg. Chem. 2008, 47, 3700-3708

73. Kerbellec, N.; Catala, L.; Daiguebonne, C.; Gloter, A.; Stephan, O.; Bünzli, J. C. G.; Guillou, O.; Mallah, T., Luminescent Coordination Nanoparticles. New J. Chem. 2008, 32, 584-587.

74. Le Natur, F.; Calvez, G.; Freslon, S.; Daiguebonne, C.; Bernot, K.; Guillou, O., Extending the lanthanide terephthalate system : isolation of an unprecedented $\mathrm{Tb}(\mathrm{III})$-based coordnation polmer with high potential porosity and luminescence properties. J. Mol. Struc. 2015, 1086, 34-42.

75. do Nascimento, J. F. S.; de Araujo, A. M. U.; de Farias Montero, A. F.; Junior, S. A.; Barros, B. S., Solid-state tunable photoluminescence in gadolinium-organic frameworks : effects of the Eu3+ content and co-doping with Tb3+. New J. Chem. 2018, 42, 5514-5522. 
76. Serwy, I. B.; Wanderlay, K. A.; Lucena, M. A. M.; Maldaner, A. O.; Talhavini, M.; Rodrigues, M. O.; Weber, I. T., $\left[\operatorname{Ln}_{2}(B D C)_{3}\left(\mathrm{H}_{2} \mathrm{O}\right)_{4}\right]_{n}$ : A low cost alternative for GSR luminescent marking. J. Lumin. 2018, 200, 24-29.

77. Serre, C.; Millange, F.; Thouvenot, C.; Gardant, N.; Pelle, F.; Ferey, G., Synthesis, characterization and luminescent properties of a new three-dimensionnal lanthanide trimesate : $\mathrm{M}((\mathrm{C} 6 \mathrm{H} 3)-(\mathrm{CO} 2) 3)(\mathrm{M}=\mathrm{Y}, \mathrm{Ln})$ or MIL-78. J. Mater. Chem. 2004, 14, 1540-1543.

78. Serre, C.; Millange, F.; Surblé, S.; Férey, G., A Route to the Synthesis of Trivalent Transition Metal Porous Carboxylates with Trimesic Secondary Building Units. Angew. Chem. Int. Ed. 2004, 43, 6286-6289.

79. Serre, C.; Millange, F.; Thouvenot, C.; Gardant, N.; Pelle, F.; Ferey, G., Synthesis, characterization and luminescent properties of a new yhree dimensional lanthanide trimesate : $\mathrm{M}$ (btc) with $\mathrm{M}=$ Yor Ln. J. Mater. Chem. 2004, 14, 1540-1543.

80. Serre, C.; Millange, F.; Surblé, S.; Férey, G., A Route to the Synthesis of Trivalent TransitionMetal Porous Carboxylates with Trimeric Secondary Building Units. Angew. Chem. Int. Ed. 2004, 43, 6285-6289.

81. Daiguebonne, C.; Guillou, O.; Gérault, Y.; Boubekeur, K., Structural diversity in lanthanide complexes chemistry : the Ln 3+ - TMA 3- - H 2 O system. Recent Research Development in Inorganic Chemistry 2000, 2, 165-183.

82. Daiguebonne, C.; Guillou, O.; Boubekeur, K., A new family of $\operatorname{Er}(I I I)$ complexes : from chains to nanotubes. Inorg. Chim. Acta 2000, 304, 161-169.

83. Daiguebonne, C.; Guillou, O.; Gérault, Y.; Lecerf, A.; Boubekeur, K., Synthesis and crystal structure of two new rare earth trimesate complexes : $\operatorname{ErTMA}(\mathrm{H} 2 \mathrm{O}) 5.3 .5 \mathrm{H} 2 \mathrm{O}$ and $\mathrm{YTMA}(\mathrm{H} 2 \mathrm{O}) 6$. Inorg. Chim. Acta 1999, 284, 139-145.

84. Piguet, C.; Bünzli, J. C. G., Self-Assembled Lanthanide Helicates: From Basic Thermodynamics to Applications. In Handbook on the Physics and Chemistry of Rare Earths, K. A. GschneidnerJr, J.-C. G. B., V. K. Pecharsky, Ed. Elsevier Science: Amsterdam, 2010; Vol. 40, pp 301-553.

85. Faulkner, S.; Natrajan, L. S.; Perry, W. S.; Sykes, D., Sensitised luminescence in lanthanide containing arrays and d-f hybrids. Dalton Trans. 2009, 3890-3899.

86. Debroye, E.; Parac-Vogt, T. N., Towards polymetallic lanthanide complexes as dual contrast agents for magnetic resonance and optical imaging. Chem. Soc. Rev. 2014, 43, 8178-8192. 
TABLE OF CONTENT (GRAPHIC).

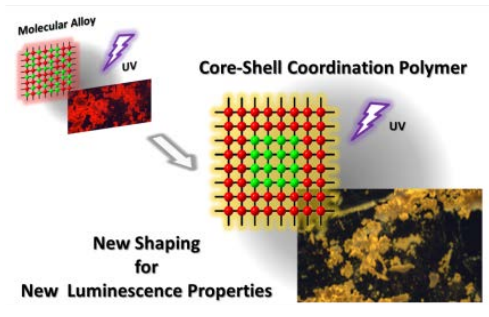

\section{TABLE OF CONTENT}

Core-shell shaped microcrystalline powders of lanthanide-based coordination polymers have been prepared and structurally characterized. Their photo-physical properties are drastically different from that exhibited by analogous classical molecular alloy samples. 